\title{
Characterisation of material and connection behaviour in sheathed cold-formed steel wall systems - Part 2: analytical modelling
}

\author{
Constantinos Kyprianou*, Pinelopi Kyvelou, Leroy Gardner, David A. Nethercot \\ Department of Civil and Environmental Engineering, Imperial College London, South Kensington Campus, \\ London $S W 72 A Z$, $U K$
}

\begin{abstract}
Analytical models to describe the material and connection behaviour of the key components of sheathed cold-formed steel wall systems are developed and assessed in the present paper. The experimental data generated and collected in the companion paper [1] are utilised for the calibration of the developed models. The assembled experimental database comprises the results of more than 400 physical tests, featuring material tests on plasterboard and oriented strand board (OSB), screw connector tests as well such as pull-through and push-out tests. The Ramberg-Osgood model [2] was shown to accurately describe the stress-strain behaviour of both plasterboard and OSB in the longitudinal and transverse direction in both tension and compression, while the Mander model [3] was also shown to accurately capture the compression behaviour for both materials and to follow the post peak unloading response. A generalised Ramberg-Osgood curve with linear post-peak unloading was adopted for describing the pull-through load-deformation behaviour of screws in OSB and plasterboard, while a similar generalised Ramberg-Osgood formulation, but with different exponents for the initial and subsequent parts of the curve was shown to accurately capture the shear load-slip behaviour of screws in steel-to-board connections. Predictive expressions for the ultimate capacities and recommended values for the remaining model parameters are provided herein. The developed predictive models are suitable for use in numerical simulations and advanced design methods.
\end{abstract}

Keywords: cold-formed steel; OSB; plasterboard; pull-through; push-out; screw connectors; sheathing 


\section{Introduction}

Wall systems comprising cold-formed steel studs and sheathing boards are widely used in the construction industry, principally due to their speed of construction, lightweight and excellent structural performance. The use of cold-formed steel for load bearing frames 5 is also growing, offering an economical and structurally efficient alternative to traditional construction for low and medium rise buildings.

The contribution of the sheathing to the strength and stiffness of stud wall systems is generally neglected in design, with the cold-formed steel studs considered as the sole load bearing components. However, the beneficial influence of sheathing is being increasingly recognised. It has been shown that sheathing boards can offer substantial lateral restraint to the columns, provided a sufficiently strong and stiff inter-connection is employed [4] 6 . Furthermore, recently conducted research [7] showed that the mobilisation of composite action between cold-formed steel sections and wood-based boards is feasible, resulting in further benefits in terms of structural performance. It is therefore recognised that, in order to enhance the structural behaviour of cold-formed steel wall systems, design needs to be driven by efficient use of materials and strategic choice of connectors.

When a sheathed wall is subjected to compressive or lateral loads - or a combination of these two - shear and pull-through forces develop at the interface between the stud and the board, leading to their relative slip and separation, respectively [8-10]. Resistance to these forces is provided by the employed connection, while rotation and twisting of the elements is restrained mainly through contact [4, 11]. It is therefore clear that a thorough understanding of the material and connector response, as well as of the interaction between the structural components of wall systems, is a prerequisite for an accurate and detailed replication of their behaviour in advanced computational and analytical modelling.

An investigation into the modelling of the material behaviour of the different components

\footnotetext{
* Corresponding author

Email addresses: constantinos.kyprianou08@imperial.ac.uk (Constantinos Kyprianou), pinelopi.kyvelou11@imperial.ac.uk (Pinelopi Kyvelou), leroy.gardner@imperial.ac.uk (Leroy Gardner), d.nethercot@imperial.ac.uk (David A. Nethercot)
} 
forming a typical wall system, as well as of the behaviour of the inter-connection in pullthrough and shear considering different sheathing and fastening arrangements, is presented herein. A comprehensive dataset comprising the results of physical tests from different sources has been assembled and presented in the companion paper [1]. The collected results are analysed in this paper and used to underpin the development of predictive models, suitable for use in numerical simulations and advanced design methods.

\section{Review of key existing formulations}

The general form of the stress-strain and load-deformation curves studied herein are characterised by an initial linear portion, followed by a rounded response up to a peak load and an unloading path. Although other expressions exist, the most widely adopted formulations to represent the above described behaviour are the Ramberg-Osgood [2] and Mander [3] type models. The two models are introduced below.

\subsection{Ramberg-Osgood model}

The Ramberg-Osgood model presented in Equation (1), which was initially devised for the constitutive modelling of aluminium [2, 12, is widely used for describing the material behaviour of metals exhibiting a rounded stress-strain curve, with no distinct yield point. A two stage version [13, 14] of the original model is now used to provide an accurate description of the stress-strain behaviour of several metals, including cold-formed steel [15], stainless steel at both room temperatures [13, 14, 16] and elevated temperatures [17] and aluminium alloys [18; the second stage was introduced to enable an accurate description of the stress-strain response of these materials over their full range, overcoming limitations in accuracy of the original expression.

The two-stage Ramberg-Osgood model, presented in Equations (1) and (2), comprises two parts: the first stage describes the stress-strain response from the origin to the $0.2 \%$ proof stress $\sigma_{0.2}$ while the second stage describes the curve from the $0.2 \%$ proof stress to the ultimate stress $\sigma_{u}$; continuity in position and slope is ensured at the intersection between the two stages. In Equations (1) and (2), $\sigma$ and $\varepsilon$ are the engineering stress and strain 
respectively, $E$ is the Young's modulus, $E_{0.2}$ is the tangent modulus at $\sigma_{0.2}, \varepsilon_{u}$ and $\varepsilon_{0.2}$ are the total strains corresponding to the ultimate and $0.2 \%$ proof stresses respectively while $n$ and $m$ are strain hardening exponents determining the degree of roundedness of the stressstrain curve.

$$
\begin{gathered}
\varepsilon=\frac{\sigma}{E}+0.002\left(\frac{\sigma}{\sigma_{0.2}}\right)^{n}, \quad \text { for } \quad \sigma \leq \sigma_{0.2} \\
\varepsilon=\frac{\sigma-\sigma_{0.2}}{E_{0.2}}+\left(\varepsilon_{u}-\varepsilon_{0.2}-\frac{\sigma_{u}-\sigma_{0.2}}{E_{0.2}}\right)\left(\frac{\sigma-\sigma_{0.2}}{\sigma_{u}-\sigma_{0.2}}\right)^{m}+\varepsilon_{0.2}, \quad \text { for } \quad \sigma_{0.2}<\sigma \leq \sigma_{u}
\end{gathered}
$$

A generalised form of the single stage Ramberg-Osgood model is illustrated in Figure 1 and given by Equation (3) where $\sigma_{x}$ and $\varepsilon_{x}$ are the stress and strain of the point through which the curve is forced to pass.

$$
\varepsilon=\frac{\sigma}{E}+\left(\varepsilon_{x}-\frac{\sigma_{x}}{E}\right)\left(\frac{\sigma}{\sigma_{x}}\right)^{n}
$$

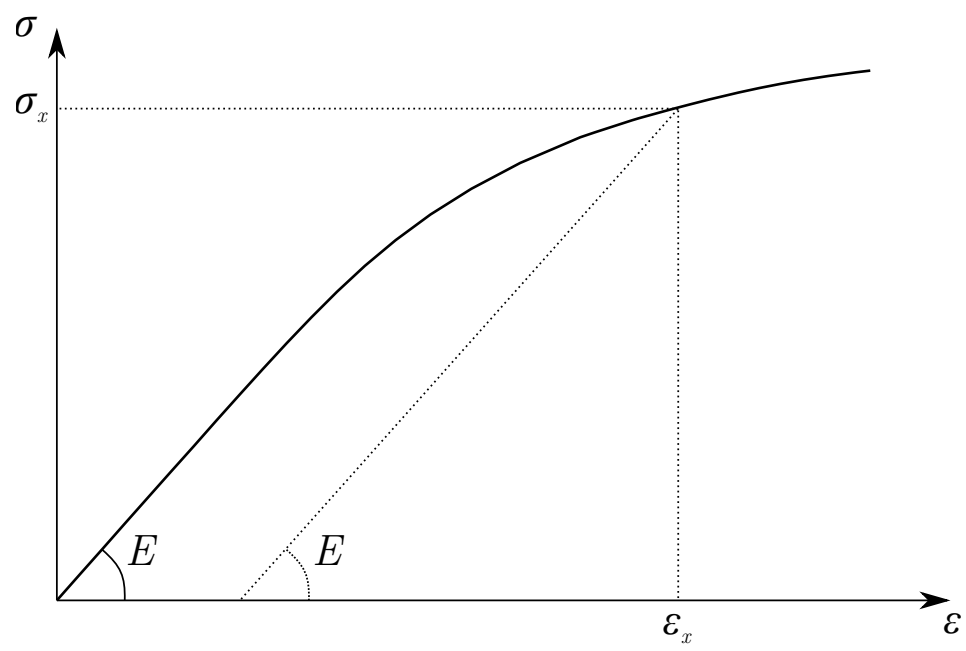

Figure 1: Generalised form of single stage Ramberg-Osgood model

\subsection{Mander model}

The Mander model [3], given by Equation (4) and illustrated in Figure 2, has been shown to be capable of accurately capturing the full stress-strain curve of confined concrete 
for various arrangements of transverse reinforcement. It accounts for both the strength enhancement due to confinement and the slope of the descending part of the material curve.

$$
\begin{gathered}
\sigma=f_{c} \frac{\varepsilon}{\varepsilon_{c}} \frac{r}{r-1+\left(\frac{\varepsilon}{\varepsilon_{c}}\right)^{r}} \text { for } 0<\varepsilon<\varepsilon_{c, u} \\
\text { with } r=\frac{E}{E-\frac{f_{c}}{\varepsilon_{c}}}
\end{gathered}
$$

In Equation (4), $f_{c}$ and $\varepsilon_{c}$ are the compressive strength and corresponding strain respectively, $\varepsilon_{c, u}$ is the final compressive strain while $r$ is defined according to Equation (5), where $E$ is the Young's modulus.

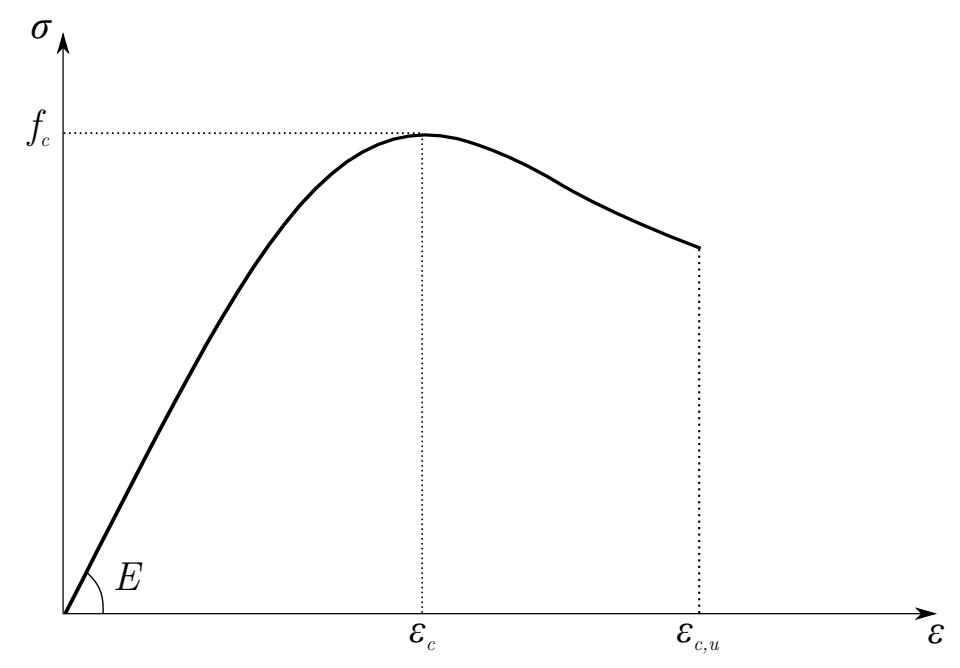

Figure 2: Mander model [3]

\subsection{Discussion}

The formulation of the Ramberg-Osgood model is such that it can only describe the ascending part of a curve, with strain expressed as a function of the stress. The RambergOsgood expressions [13-16, 18, usually provide a very accurate fit to experimental data obtained from material tests on metals with rounded stress-strain responses, since the degree of roundness can be directly captured through the strain hardening exponents $n$ and $m$. On the other hand, the response observed during compression tests on materials such as 
confined concrete can be more completely described by the Mander model since, with a single expression for stress in terms of strain, both the ascending and descending parts of the response can be captured, accounting for the post-peak capacity. Note that, in both models, three basic parameters need to be defined i.e. $E, \sigma_{0.2}$ and $n$ for the single stage Ramberg-Osgood model and $E, f_{c}$ and $\varepsilon_{c}$ for the Mander model. The suitability of these two models, and adaptations thereof, for representing the nonlinear stress-strain and loaddeformation responses studied herein, is examined throughout the present paper.

\section{Material modelling}

Describing the material response of the key components (i.e. the steel and the sheathing) of sheathed cold-formed steel wall systems is the focus of the present section. The experimental data assembled in the companion paper [1] are analysed and predictive models are developed and assessed.

\subsection{Cold-formed steel}

A model to describe the stress-strain response of cold-formed steel, based on the twostage Ramberg-Osgood formulation, was developed in [15]. Predictive expressions for the key parameters were devised based on an extensive dataset of more than 700 experiments. Use of these expressions led to stress-strain curves that could accurately capture the rounded nature of the material response obtained from tensile testing of the $1.2 \mathrm{~mm}$ thick cold-formed steel coupons presented in the companion paper [1]. However for the steel coupons of 2.0 $\mathrm{mm}$ thickness, although some degree of roundness was exhibited up to the yield point $\sigma_{0.2}$, a plateau was observed thereafter, rendering the use of the 2-stage Ramberg-Osgood model inappropriate. This supports the previous observations [15] that thinner sheet material generally undergoes a higher level of cold-work and is therefore more likely to exhibit a shorter (or no) yield plateau and a more rounded stress-strain curve. For the $2.0 \mathrm{~mm}$ thick coupons, the material model developed in [19] for hot-rolled steel, featuring a yield plateau is more appropriate. 


\subsection{Sheathing material}

\subsubsection{Plasterboard}

Plasterboard is the most commonly used sheathing material for stud wall systems. Physical tests have revealed orthotropic material behaviour, with the mechanical properties in the longitudinal direction of the panel being higher compared to those in the transverse direction. Numerous material test results have been reported in the literature, both in tension and compression - a summary of these is presented in [1].

Petrone et al. [20] proposed the use of a bilinear stress-strain curve to describe the response of plasterboard material in tension while, when subjected to compression, use of the Mander model [3] was recommended. The data used for the model derivation in [20] were limited to the experimental results conducted by the authors themselves. A broader dataset of 147 material tests [1, 20, 21], has been assembled in the companion paper [1] and is employed herein to assess the suitability of existing models presented in the literature, along with new predictive models proposed herein. A summary of the assembled dataset is provided in Table 18 of the companion paper. Note that particular attention was given during the model derivation to maintaining a balance between accuracy and simplicity, such that all key aspects of the material behaviour are captured while limiting the required number of input parameters.

Following analysis of the experimental results, the model presented in Equation (6) has been established for modelling the material behaviour of plasterboard, both in tension and compression. The proposed model is based on the Ramberg-Osgood (R-O) formulation presented in Equation (3), appropriately adapted to fit the experimental curves. It should be mentioned that, when modelling the material response of plasterboard under compression, both the Mander [3] model presented in Equation (4) and the Ramberg-Osgood expression presented in Equation (6) were found capable of providing good fits to the experimental data, though the Ramberg-Osgood material was more accurate for individual specimens up to the peak stress owing to the ability to change the value of $n$ to alter the degree of 
roundedness of the curve.

$$
\varepsilon=\frac{\sigma}{E}+\left(\varepsilon_{u}-\frac{f_{u}}{E}\right)\left(\frac{\sigma}{f_{u}}\right)^{n}
$$

The parameters employed in Equation (6) are the Young's modulus E (calculated as the slope of the curve between the points corresponding to $10 \%$ and $40 \%$ of the ultimate strength), the ultimate strength $f_{u}$, its corresponding strain $\varepsilon_{u}$ and $n$, which is the exponent controlling the degree of roundness of the curve; these have been determined as the average values for the full examined dataset and are reported in Table1. Note that the model can be used for describing the material behaviour of plasterboard both in tension and compression and in the longitudinal and transverse directions, by employing the corresponding values of $E, f_{u}, \varepsilon_{u}$ and $n$.

Comparisons between the normalised experimental stress-strain curves on $12.5 \mathrm{~mm}$ and $15.0 \mathrm{~mm}$ thick plasterboard and the proposed model are shown in Figure 3, where the model can be seen to accurately capture the material response of the plasterboard in both directions (i.e. longitudinal and transverse) and loading configurations (i.e. tension and compression). Comparisons against the Mander model (given by Equation (4) for which $f_{c}=f_{u}$ and $\varepsilon_{c}=\varepsilon_{u}$ ), employed as recommended in [20] for specimens in compression only and plotted up to $80 \%$ of $f_{u}$ post-peak, are also shown in Figure 3 since this model has been also found to provide a good fit to the test curves. Note that the test results presented in Figure 3 are normalised against their respective values of $f_{u}$ and $\varepsilon_{u}$ to allow all curves to be shown together. Finally, the material models for plasterboard under compression and tension for both directions (i.e. longitudinal and transverse), presented for the average measured mechanical properties reported in Table 1, are shown in Figure 4. 


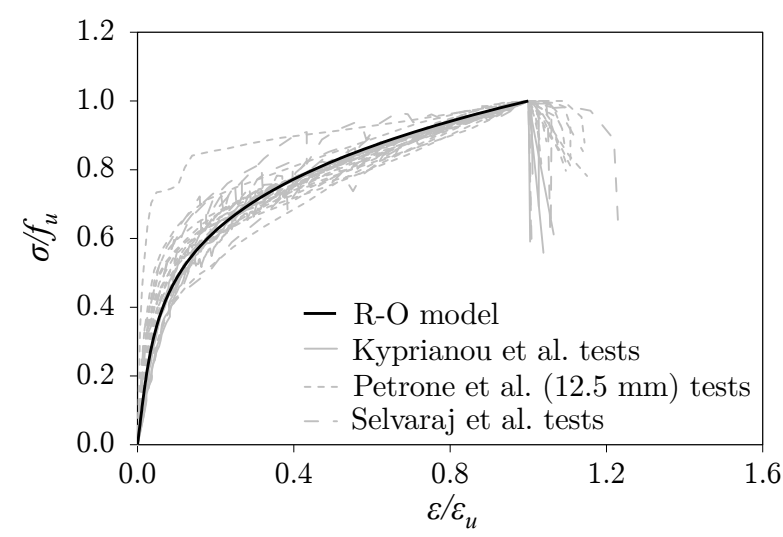

(a) Tension, longitudinal

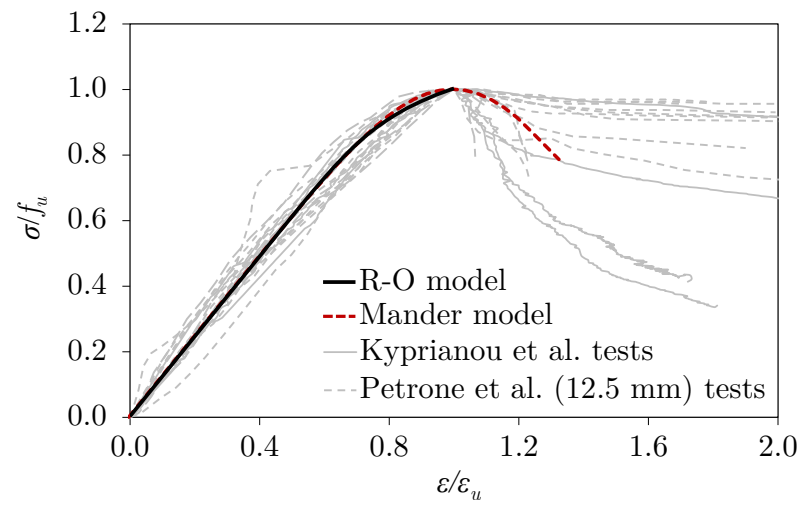

(c) Compression, longitudinal

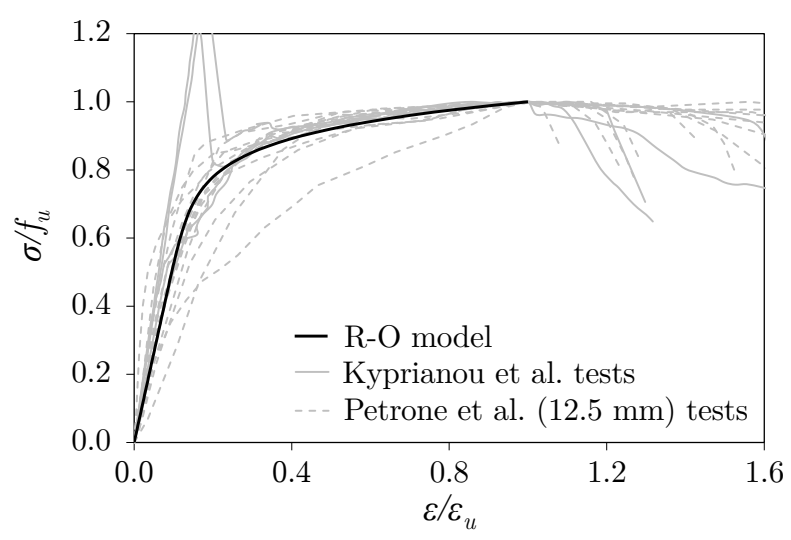

(b) Tension, transverse

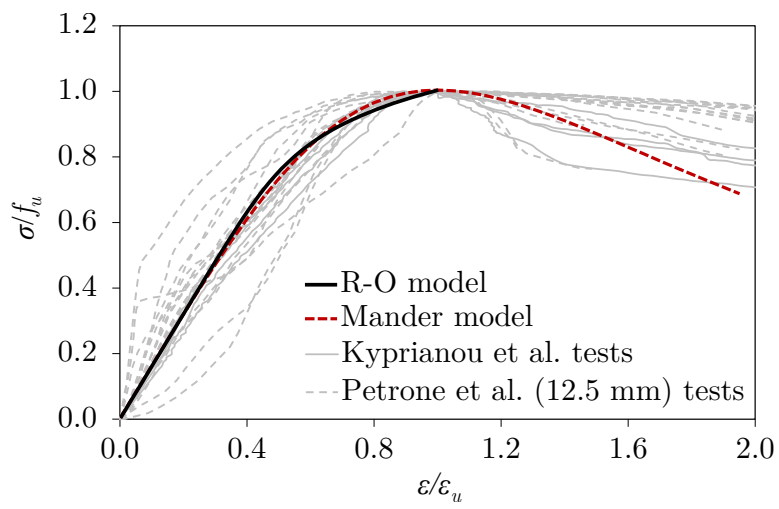

(d) Compression, transverse

Figure 3: Comparison of the proposed model for plasterboard with normalised test curves for specimens of 12.5-15.0 mm thickness in (a-b) tension and (c-d) compression

Table 1: Averaged measured material properties of plasterboard

\begin{tabular}{cllccccccccc}
\hline \multirow{2}{*}{$\begin{array}{c}\text { Thickness } \\
(\mathrm{mm})\end{array}$} & \multirow{2}{*}{ Loading } & Direction & \multicolumn{2}{c}{$E(\mathrm{MPa})$} & \multicolumn{2}{c}{$f_{u}(\mathrm{MPa})$} & \multicolumn{2}{c}{$\varepsilon_{u}(\%)$} & \multicolumn{3}{c}{$n$} \\
\hline \multirow{3}{*}{$12.5-15.0$} & & Mean & COV & Mean & COV & Mean & COV & Mean & COV \\
\cline { 3 - 11 } & \multirow{2}{*}{ Tension } & Longitudinal & 1940 & 0.30 & 1.66 & 0.17 & 0.90 & 0.31 & 4.0 & 0.18 \\
& & Transverse & 1570 & 0.32 & 0.77 & 0.10 & 0.43 & 0.48 & 10.7 & 0.26 \\
\cline { 3 - 11 } & \multirow{2}{*}{ Compression } & Longitudinal & 2390 & 0.23 & 3.40 & 0.09 & 0.20 & 0.16 & 10.2 & 0.16 \\
& & Transverse & 2130 & 0.41 & 3.08 & 0.05 & 0.29 & 0.28 & 7.9 & 0.16 \\
\hline
\end{tabular}




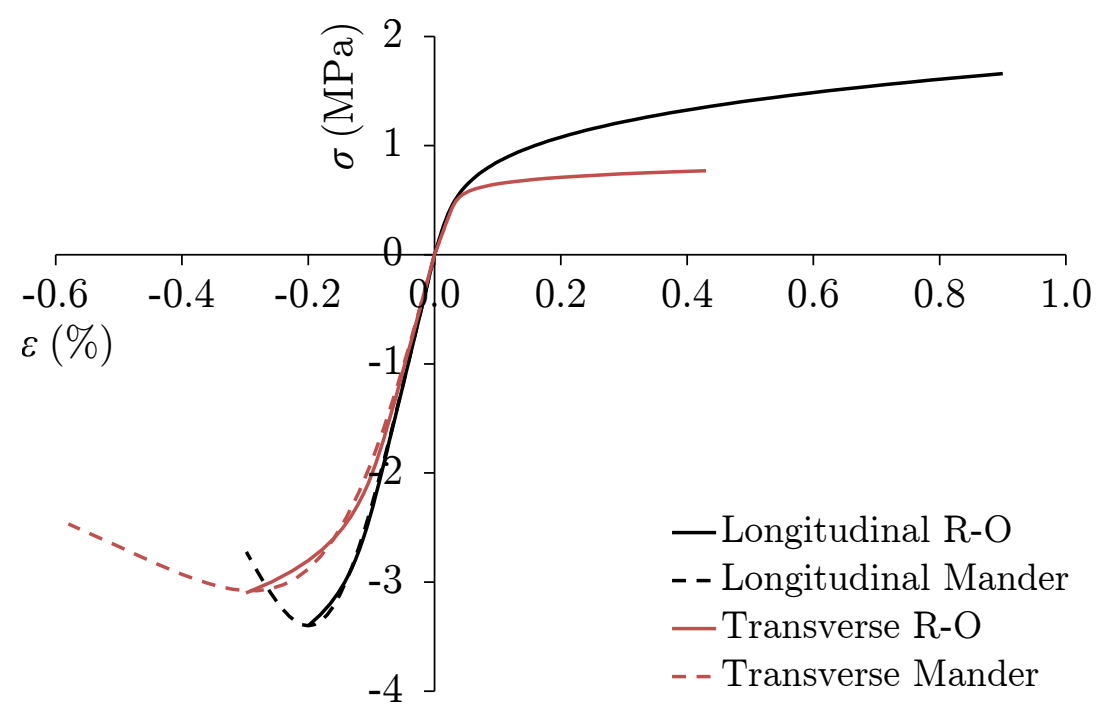

Figure 4: The Ramberg-Osgood (R-O) and Mander models using the average measured material properties of plasterboard, with positive values of stress and strain signifying tension (where only the R-O model is used) and negative values signifying compression (where both the R-O and Mander models are shown)

\subsubsection{Oriented Strand Board}

Oriented strand boards (OSB) are frequently used as sheathing panels in wall systems due to their durability. Although several studies have been conducted [22 24] to determine the mechanical properties of OSB material, few models describing the observed stress-strain response have been devised. A parabolic stress-strain curve was proposed in [22] and [24] for OSB while the single Ramberg-Osgood formulation was adapted in [25] to describe the stress-strain behaviour of wood-based particle boards. Aiming at the establishment of a material model for OSB derived on the basis of a wider experimental dataset, results from 195 material tests on OSB have been assembled in [1] and are employed herein; these are summarised in Table 19 of the companion paper.

The Ramberg-Osgood formulation provided in Equation (6) has been adopted for the description of the material response of OSB; the definitions of the employed parameters are provided in Section 3.2.1. The proposed model can be used for both directions (i.e. longitudinal and transverse) and load configurations (i.e. tension and compression), using the respective mechanical properties. A summary of the average measured mechanical properties 
of the examined dataset is presented in Table 2 .

The normalised experimental stress-strain curves and the proposed model given by Equation (6) are compared in Figure 5 where the model is shown to accurately capture the exhibited behaviour in both the longitudinal and transverse directions, both in tension and compression. Note that the presented curves are normalised against their respective ultimate strength $f_{u}$ and corresponding strain $\varepsilon_{u}$. In a similar fashion to the plasterboard specimens tested under compression, the Mander [3] model, plotted up to $80 \%$ of $f_{u}$ post-peak, was also fitted to the data from the OSB specimens tested under compression and was found to also provide a good fit. The material models for OSB under compression and tension for both directions (i.e. longitudinal and transverse), presented based on the average measured mechanical properties reported in Table 2, are shown in Figure 6.

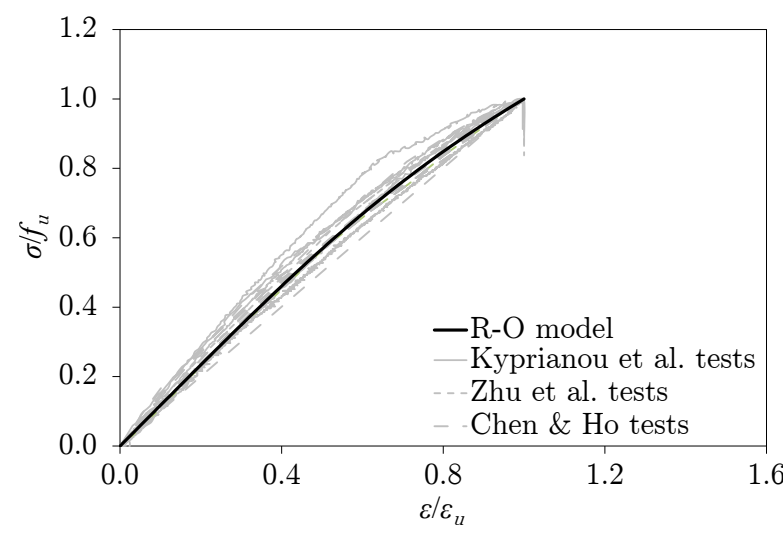

(a) Tension, longitudinal

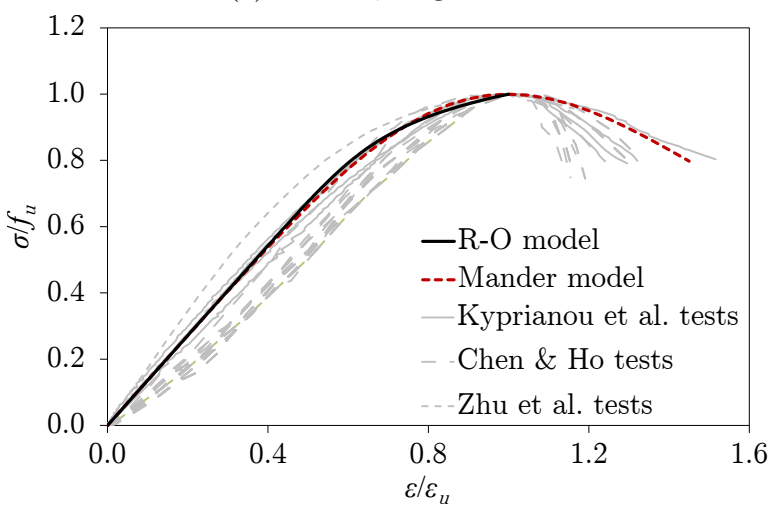

(c) Compression, longitudinal

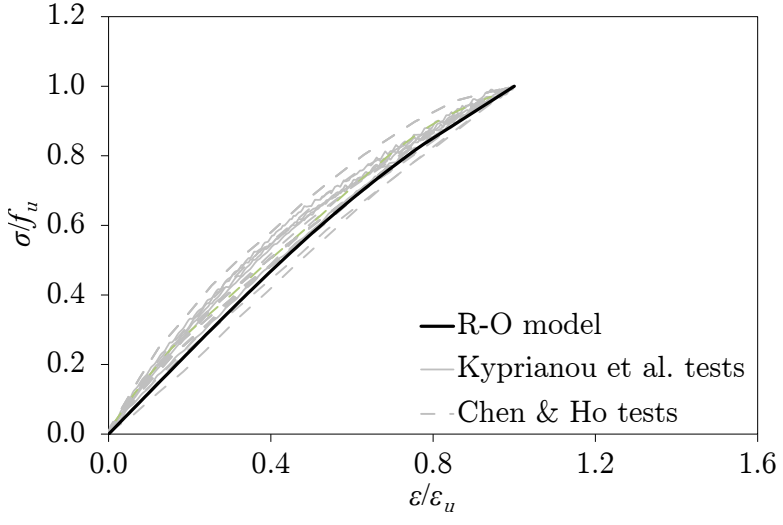

(b) Tension, transverse

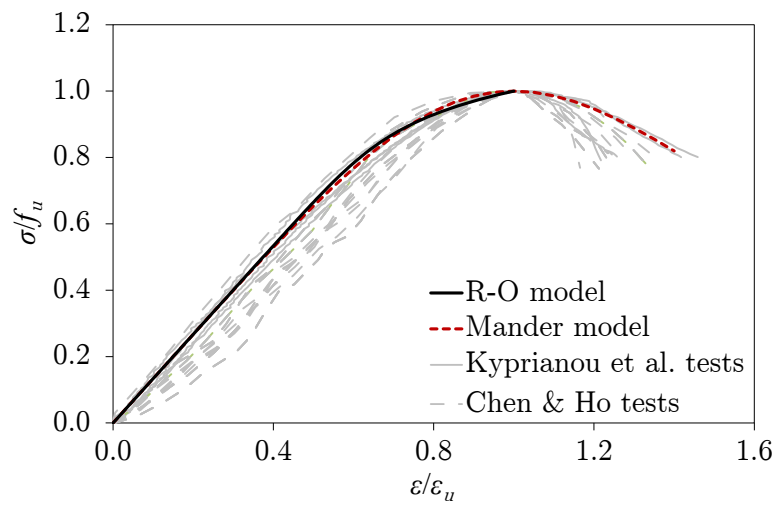

(d) Compression, transverse

Figure 5: Comparison of the proposed model for OSB with the obtained normalised test curves in both directions in (a-b) tension and (c-d) compression 
Table 2: Averaged measured material properties of OSB

\begin{tabular}{llllllllll}
\hline \multirow{2}{*}{ Loading } & \multirow{2}{*}{ Direction } & \multicolumn{2}{c}{$E(\mathrm{MPa})$} & \multicolumn{2}{c}{$f_{u}(\mathrm{MPa})$} & \multicolumn{2}{c}{$\varepsilon_{u}(\%)$} & \multicolumn{2}{c}{$n$} \\
& & Mean & COV & Mean & COV & Mean & COV & Mean & COV \\
\hline \multirow{3}{*}{ Tension } & Longitudinal & 3670 & 0.19 & 11.9 & 0.08 & 0.38 & 0.08 & 4.2 & 0.06 \\
& Transverse & 2640 & 0.20 & 8.4 & 0.19 & 0.38 & 0.18 & 4.0 & 0.09 \\
& A $45^{\circ}$ & 3180 & 0.15 & 9.7 & 0.10 & 0.36 & 0.12 & 4.0 & 0.10 \\
\hline \multirow{3}{*}{ Compression } & Longitudinal & 3430 & 0.10 & 13.4 & 0.07 & 0.53 & 0.15 & 11.5 & 0.11 \\
& Transverse & 2580 & 0.09 & 11.4 & 0.10 & 0.59 & 0.16 & 12.0 & 0.10 \\
& At $45^{\circ}$ & 2840 & 0.08 & 12.8 & 0.06 & 0.57 & 0.10 & 12.0 & 0.10 \\
\hline
\end{tabular}

—Longitudinal R-O

- - Longitudinal Mander

- Transverse R-O

- - Transverse Mander

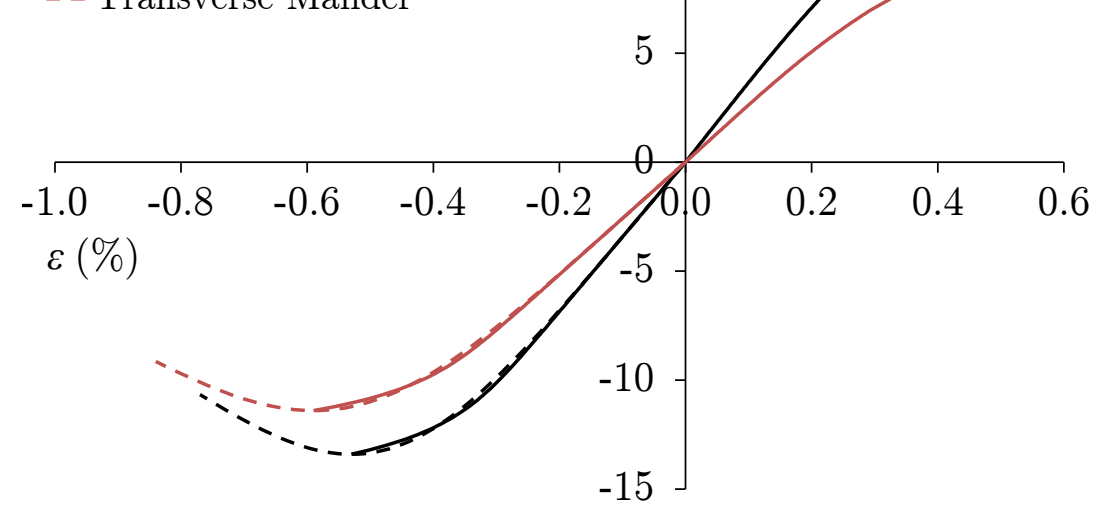

Figure 6: The Ramberg-Osgood (R-O) and Mander models using the average measured material properties of OSB, with positive values of stress and strain signifying tension (where only the R-O model is used) and negative values signifying compression (where both the R-O and Mander models are shown)

\section{Modelling of interaction between components}

The characteristics of the connectors employed within a stud wall system have been shown to play a significant role in the exhibited structural response, since, depending on their arrangement, they can provide effective bracing and mobilise composite action [5, 9, 26- 
wall systems, are the focus of the present study; their interaction with the steel studs and sheathing panels is examined in this section.

\subsection{Pull-through load-deformation response}

Although pull-through failures of steel stud-to-sheathing connectors have been reported by several researchers [5, 30, 31], experiments focusing solely on this type of failure are very limited. In the companion paper [1, a series of 25 pull-through tests was conducted and presented in detail; the obtained results are used herein as the basis for the derivation of a predictive model to describe the load-deformation response. Note that the pull-through deformation reported in the examined test results is the net embedment of the screw $\delta_{p t}$, as indicated in Figures 19 and 21 of the companion paper.

\subsubsection{Pull-through load-deformation model}

A generalised form of the Ramberg-Osgood expression, which has been used thus far for modelling the examined material responses, was also found to be capable of accurately capturing the shape of the pull-through load-deformation curves presented in [1] up to the ultimate capacity $F_{u, p t}$. The post-peak response can be described by a straight line passing from the peak point to a point corresponding to $80 \%$ of $F_{u, p t}$ post-peak (i.e. point $\left(\delta_{u, p t, 0.8}\right.$, $\left.\left.F_{u, p t, 0.8}\right)\right)$. Note that for the specimens comprising two boards, which were found to exhibit a second peak (i.e. $F_{u, p t, 2}$ at a displacement $\delta_{u, p t, 2}$ ) [1], use of an additional linear part can be used for modelling the response between $F_{u, p t, 0.8}$ and $F_{u, p t, 2}$ - see Figure 7. The modified Ramberg-Osgood expression and the bilinear expression post $F_{u, p t}$ proposed herein for the modelling of the pull-through load-deformation characteristics of screw connectors, is provided by Equation (7) and illustrated in Figure 7 .

$$
\delta_{p t}= \begin{cases}\frac{F_{p t}}{K_{o, 40}}+\left(\delta_{u, p t}-\frac{F_{u, p t}}{K_{o, 40}}\right)\left(\frac{F_{p t}}{F_{u, p t}}\right)^{n} & \text { for } \quad \delta_{p t} \leq \delta_{u, p t} \\ \delta_{u, p t}+\left(F_{p t}-F_{u, p t}\right)\left(\frac{\delta_{u, p t, 0.8}-\delta_{u, p t}}{F_{u, p t, 0.8}-F_{u, p t}}\right) & \text { for } \quad \delta_{u, p t}<\delta_{p t} \leq \delta_{u, p t, 0.8} \\ \delta_{u, p t, 0.8}+\left(F_{p t}-F_{u, p t, 0.8}\right)\left(\frac{\delta_{u, p t, 2}-\delta_{u, p t, 0.8}}{F_{u, p t, 2}-F_{u, p t, 0.8}}\right) & \text { for } \quad \delta_{u, p t, 0.8}<\delta_{p t} \leq \delta_{u, p t, 2}\end{cases}
$$


In Equation (7), $\delta_{p t}$ is the pull-through deformation, $F_{p t}$ is the load, $K_{o, 40}$ is the secant stiffness calculated at $0.4 F_{u, p t}$ and $n$ is the exponent controlling the roundedness of the curve.

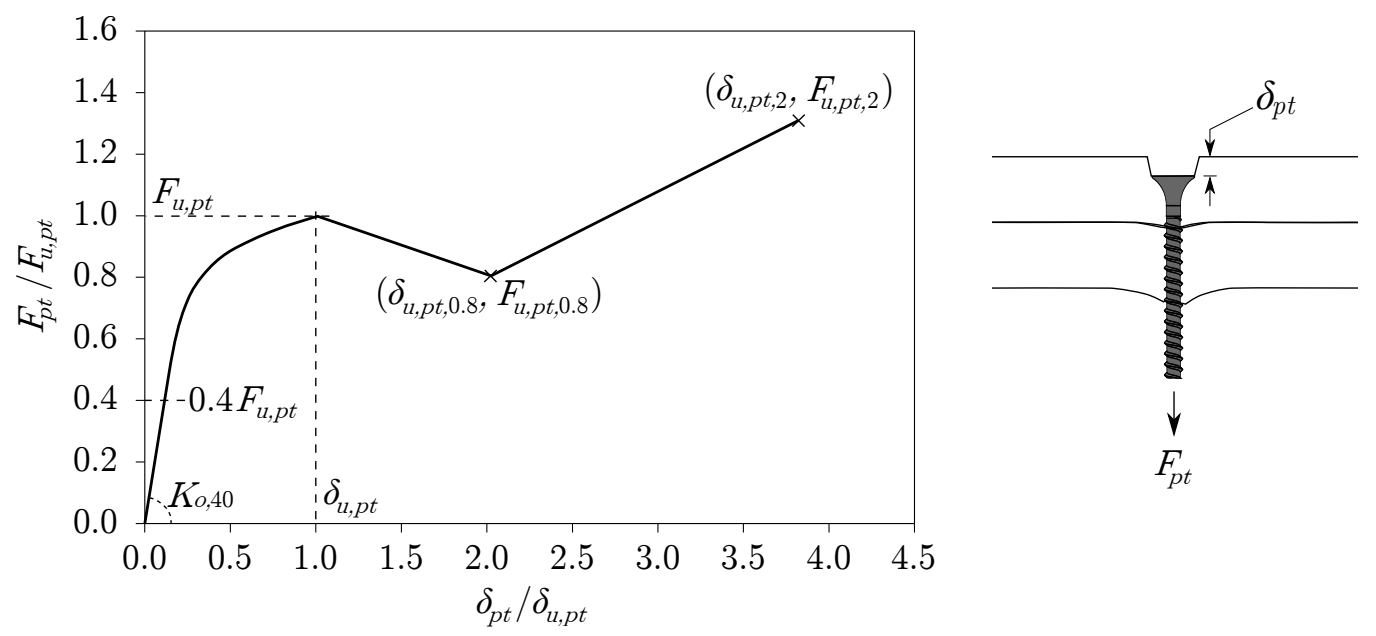

Figure 7: Pull-through load-deformation model

\subsubsection{Calculation of key parameters for pull-through load-deformation model}

Analysis of the test results revealed that the resistance of the examined connectors in pull-through depends on the combined effect of the connector head bearing into the surface of the board and the screw threads interacting with the board material. Based on these observations, Equation (8) has been devised for the calculation of $F_{u, p t}$, where $A_{p t}$ is the total bearing area during pull-through and $f_{u}$ is the compressive strength of the board material, taken herein as the average of measured values for the longitudinal and transverse directions. The average value of $f_{u}$ for each group of tests is provided in Table 3 where the designations for the groups of tests start with the letters PT, followed by the screw diameter in $\mathrm{mm} \times 10$, then the number of board layers and finally the type of material (with $\mathrm{P}$ for plasterboard and $\mathrm{O}$ for OSB).

$$
F_{u, p t}=A_{p t} f_{u}
$$

The bearing area $A_{p t}$ consists of three components, as described by Equation (9):

$$
A_{p t}=A_{s, t h r}+A_{s, h d}+A_{s, e f f}
$$


where $A_{s, t h r}$ is the contribution by the threads given by Equations $(10)$ and $(11)$ :

$$
\begin{aligned}
A_{s, t h r} & =A_{s, t h r, 1}\left(t_{b}-h_{s, h d}-s_{s, n o n t h r}\right) / s_{s, t h r} \\
\text { in which } \quad A_{s, t h r, 1} & =\pi\left[\left(d_{s, t h r} / 2\right)^{2}-\left(d_{s, s h} / 2\right)^{2}\right]
\end{aligned}
$$

$A_{s, h d}$ is the area directly below the head of the screw given by Equation (12):

$$
A_{s, h d}=\pi\left[\left(d_{s, h d} / 2\right)^{2}-\left(d_{s, t h r} / 2\right)^{2}\right]
$$

$A_{s, e f f}$ is an effective area around $A_{s, h d}$, defined by means of the angle $\theta_{s, e f f}$ shown in Figure 8, as given by Equation (13):

$$
\begin{aligned}
& A_{s, \text { eff }}=\pi\left[\left(d_{s, h d} / 2+l_{s, \text { eff }}\right)^{2}-\left(d_{s, h d} / 2\right)^{2}\right] \\
\text { where } \quad l_{s, \text { eff }} & =h_{s, h d} \tan \theta_{s, \text { eff }}
\end{aligned}
$$

It should be mentioned that the area $A_{s, \text { eff }}$ has been established to account for the conical failure surfaces observed in the pull-through tests presented in [1] while the angle $\theta_{s, e f f}$ was found to be dependent on the shape of the screw head, with the screws of $3.5 \mathrm{~mm}$ diameter having flatter heads (compared to the screws of $4.8 \mathrm{~mm}$ and $5.5 \mathrm{~mm}$ diameter) and thus higher values of $\theta_{s, e f f}$. The recommended values of $\theta_{s, e f f}$ for the different screw types have been determined based on the dataset presented in [1] and are reported in Table 3. The aforementioned areas can be determined using Equations (10) to (14) while their graphical illustration, along with the employed screw geometry notation, are provided in Figure 8.

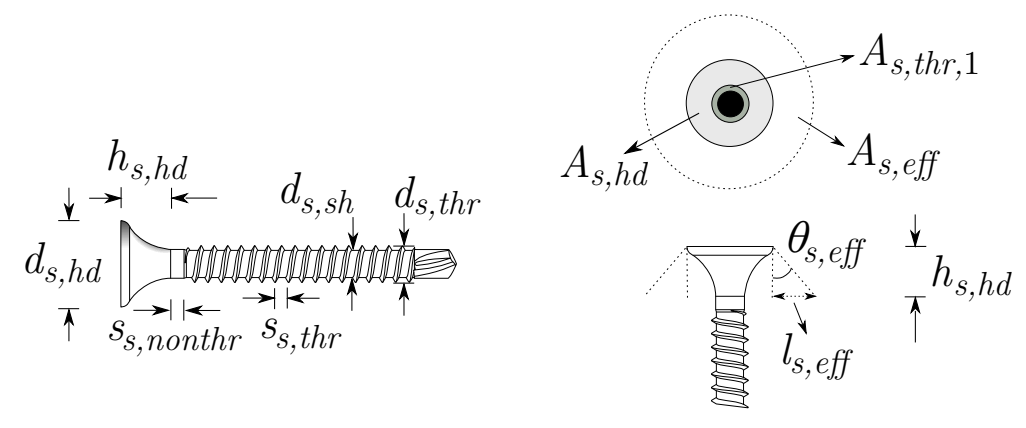

Figure 8: Screw connector geometry and bearing pull-through areas

The calculated $F_{u, p t}$ values, for the screws tested in [1], together with the contributing areas determined using Equations (10) to (14) are summarised in Table 3. Good agreement 
between the calculated and test values of $F_{u, p t}$ is demonstrated in Figure 9 , with the average ratio of the test to calculated $F_{u, p t}$ values being 0.99 with a COV of 0.11 .

Table 3: Calculated pull-through capacity $F_{u, p t}$ and key contributing properties for screws tested in [1]

\begin{tabular}{ccccccc}
\hline Designation & Average $f_{u}\left(\mathrm{~N} / \mathrm{mm}^{2}\right)$ & $\theta_{s, e f f}\left({ }^{\circ}\right)$ & $A_{s, t h r}\left(\mathrm{~mm}^{2}\right)$ & $A_{s, h d}\left(\mathrm{~mm}^{2}\right)$ & $A_{s, \text { eff }}\left(\mathrm{mm}^{2}\right)$ & $F_{u, p t}(\mathrm{kN})$ \\
\hline PT-35-1P & 3.57 & 30 & 27.3 & 45.3 & 62.1 & 0.48 \\
PT-35-2P & 3.57 & 30 & 72.9 & 45.3 & 62.1 & 0.64 \\
PT-55-1P & 3.57 & 10 & 42.4 & 63.7 & 28.1 & 0.48 \\
PT-55-2P & 3.57 & 10 & 125.2 & 63.7 & 28.1 & 0.78 \\
PT-48-1O & 11.4 & 10 & 39.5 & 60.8 & 23.8 & 1.41 \\
\hline
\end{tabular}

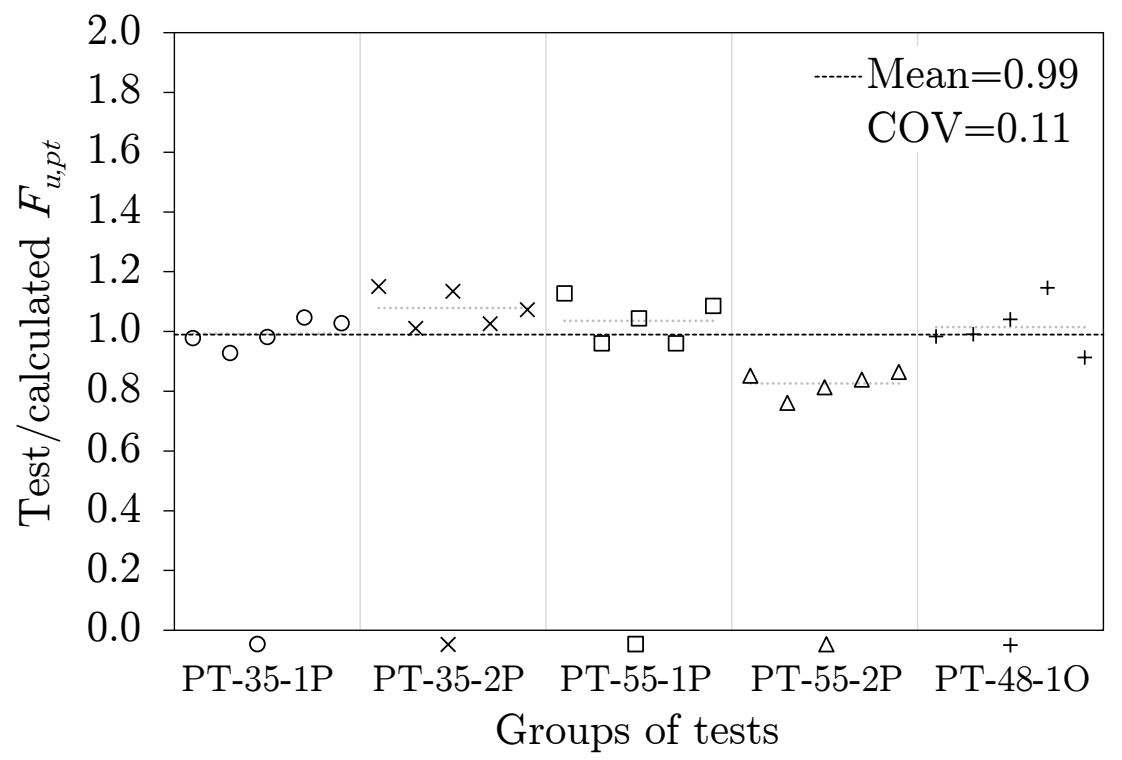

Figure 9: Comparison between experimental and calculated values of $F_{u, p t}$

Regarding the other input parameters required for the proposed pull-through loaddeformation model given by Equation (7), namely the stiffness $K_{o, 40}$ and ultimate displacement $\delta_{u, p t}$, recommended average values, expressed as a function of the nominal screw diameter $d$ and overall board thickness $t_{b}$ are provided in Table 4. The average measured post-peak displacement $\delta_{u, p t, 0.8}$, as well as the second-peak displacement $\delta_{u, p t, 2}$ for the two layer specimens, are also provided in terms of $t_{b}$, while the loads $F_{u, p t, 0.8}$ and $F_{u, p t, 2}$ are expressed in terms of the experimental pull-through load $F_{u, p t}$. Note that for the specimens 
with $5.5 \mathrm{~mm}$ diameter screws and two board layers (PT-55-2P), since no more than 5\% decreases in $F_{u, p t}$ were observed, $F_{u, p t, 0.8}$ was taken as $0.95 F_{u, p t}$ (rather than $0.8 F_{u, p t}$ ). In the absence of experimental data, representative values for the key parameters are also provided in Table 4 ,

Table 4: Average measured properties for tested screws expressed in terms of screw diameter $d$, overall board thickness $t_{b}$ and $F_{u, p t}$; recommended representative values for the key model parameters are also provided.

\begin{tabular}{|c|c|c|c|c|c|c|c|c|c|}
\hline Designation & $d(\mathrm{~mm})$ & $t_{b}(\mathrm{~mm})$ & & $K_{o, 40} / d^{2}\left(\mathrm{kN} / \mathrm{mm}^{3}\right)$ & $\delta_{u, p t} / t_{b}$ & $F_{u, p t, 0.8} / F_{u, p t}$ & $\delta_{u, p t, 0.8} / t_{b}$ & $F_{u, p t, 2} / F_{u, p t}$ & $\delta_{u, p t, 2} / t_{b}$ \\
\hline \multirow{2}{*}{ PT-35-1P } & \multirow{2}{*}{3.5} & \multirow{2}{*}{12.5} & Mean & 0.85 & 0.026 & 0.80 & 0.033 & - & - \\
\hline & & & $\mathrm{COV}$ & 0.13 & 0.214 & 0.00 & 0.090 & - & - \\
\hline \multirow{2}{*}{ PT-55-1P } & \multirow{2}{*}{5.5} & \multirow{2}{*}{12.5} & Mean & 0.47 & 0.010 & 0.80 & 0.014 & - & - \\
\hline & & & $\mathrm{COV}$ & 0.14 & 0.330 & 0.00 & 0.293 & - & - \\
\hline \multirow{2}{*}{ PT-48-1O } & \multirow{2}{*}{4.8} & \multirow{2}{*}{11.0} & Mean & 0.80 & 0.049 & 0.80 & 0.218 & - & - \\
\hline & & & $\mathrm{COV}$ & 0.04 & 0.250 & 0.00 & 0.095 & - & - \\
\hline \multirow{2}{*}{ PT-35-2P } & \multirow{2}{*}{3.5} & \multirow{2}{*}{25.0} & Mean & 1.34 & 0.036 & 0.80 & 0.081 & 1.09 & 0.26 \\
\hline & & & $\mathrm{COV}$ & 0.10 & 0.075 & 0.00 & 0.141 & 0.05 & 0.17 \\
\hline \multirow{2}{*}{ PT-55-2P } & \multirow{2}{*}{5.5} & \multirow{2}{*}{25.0} & Mean & 0.85 & 0.056 & 0.95 & 0.077 & 1.36 & 0.20 \\
\hline & & & $\mathrm{COV}$ & 0.21 & 0.128 & 0.02 & 0.071 & 0.07 & 0.14 \\
\hline \multicolumn{4}{|c|}{ Recommended representative values } & 0.80 & 0.035 & 0.80 & 0.075 & 1.20 & 0.20 \\
\hline
\end{tabular}

\subsubsection{Assessment of proposed pull-through model against experimental data}

The proposed pull-through model was validated against the test curves reported in [1]; typical comparisons between the model predictions and test curves for single- and doublelayer specimens are presented in Figures 10 and 11 respectively, where the load $F_{p t}$, normalised by $F_{u, p t}$, is plotted against the pull-through deformation $\delta_{p t}$, normalised by $\delta_{u, p t}$. It can be observed that the devised expression using average measured values for the model parameters (summarised in Table 5) provides a very good fit to the experimental curves and is therefore suitable for use in numerical simulations and advanced design models. Pull-through load-deformation curves based on calculated values of $F_{u, p t}$ and the recommended values for the key model parameters given in Table 4, along with a value of $n=8$ for all curves, are also plotted in Figures 10 and 11 for comparison. The normalised load-deformation curves obtained using the recommended representative values for the parameters generally provide a good match with the experimental results, particularly up to the ultimate load $F_{u, p t}$, with 
the exception of the PT-55-1P case shown in Figure 10 (b), where the test ultimate displacement is somewhat lower than the recommended representative value; in the presented normalised format, this creates the impression of a substantial deviation in initial stiffness, though this is not in fact the case when the curves are compared in their unnormalised form.

Table 5: Average measured values of model parameters, as determined from pull-through tests

\begin{tabular}{|c|c|c|c|c|c|c|c|c|}
\hline Designation & $K_{o, 40}(\mathrm{kN} / \mathrm{mm})$ & $F_{u, p t}(\mathrm{kN})$ & $\delta_{u, p t}(\mathrm{~mm})$ & $F_{u, p t, 0.8}(\mathrm{kN})$ & $\delta_{u, p t, 0.8}(\mathrm{~mm})$ & $F_{u, p t, 2}(\mathrm{kN})$ & $\delta_{u, p t, 2}(\mathrm{~mm})$ & $n$ \\
\hline PT-35-1P & 10.5 & 0.48 & 0.33 & 0.38 & 0.41 & - & - & 10.5 \\
\hline PT-55-1P & 14.2 & 0.50 & 0.12 & 0.40 & 0.18 & - & - & 5.5 \\
\hline PT-48-1O & 18.5 & 1.44 & 0.54 & 1.15 & 2.40 & - & - & 7.5 \\
\hline PT-35-2P & 16.5 & 0.69 & 0.89 & 0.55 & 2.03 & 0.76 & 6.43 & 5.0 \\
\hline PT-55-2P & 25.6 & 0.64 & 1.41 & 0.61 & 1.93 & 0.86 & 4.96 & 12.0 \\
\hline
\end{tabular}

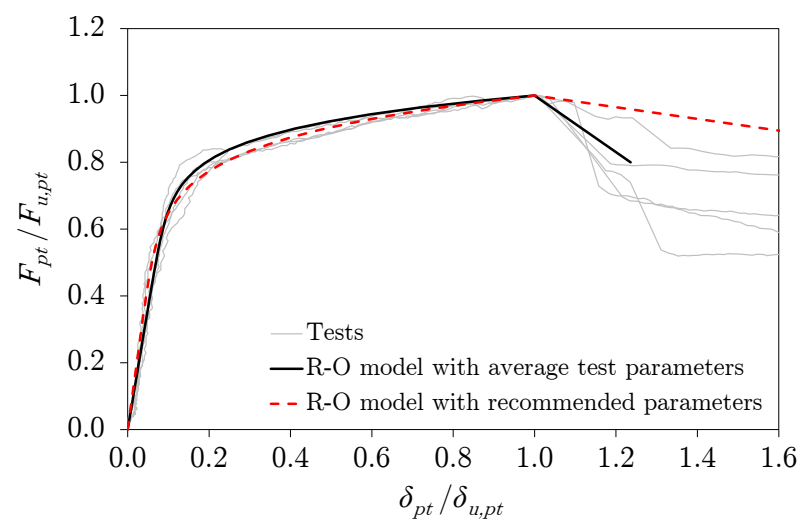

(a) PT-35-1P

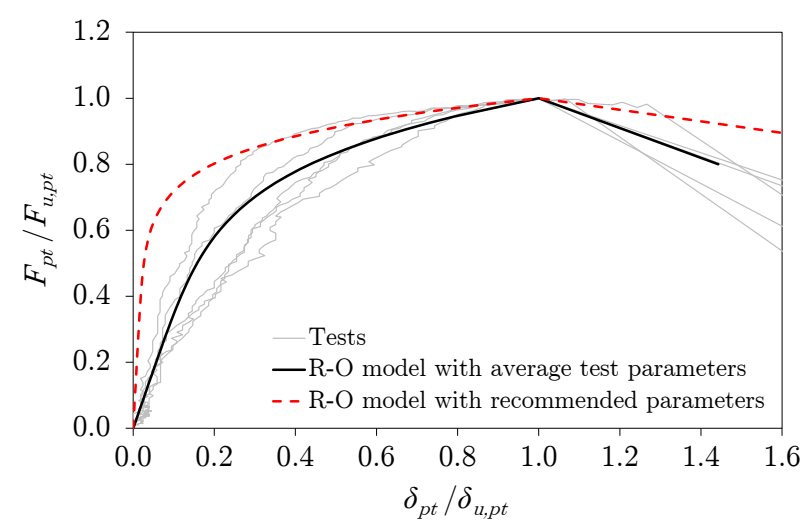

(b) PT-55-1P

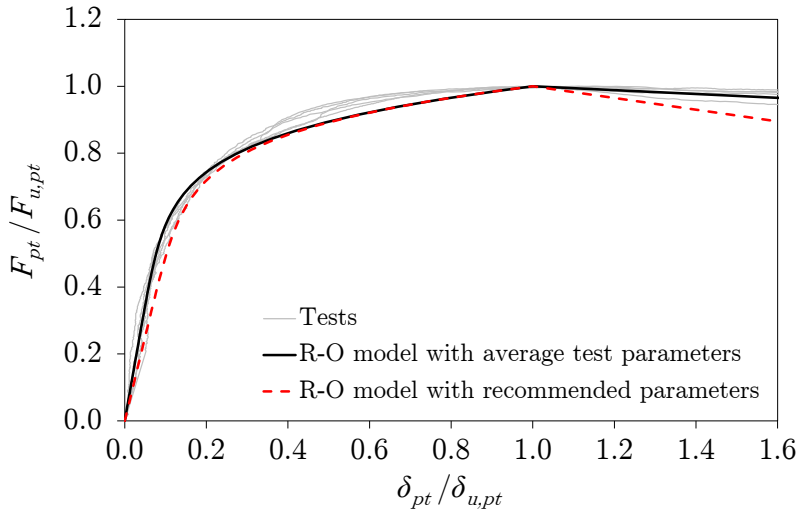

(c) PT-48-1O

Figure 10: Comparisons of the proposed model using test and recommended predicted input parameters with test curves for single board specimens 


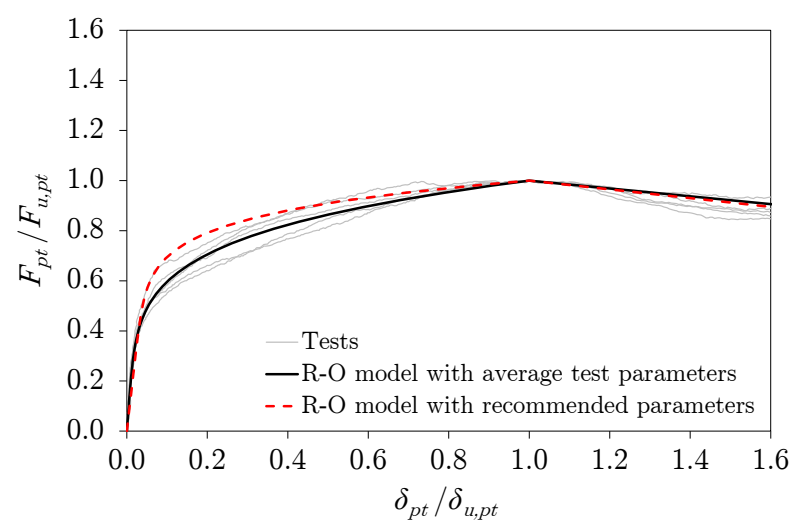

(a) PT-35-2P, detail of the first peak

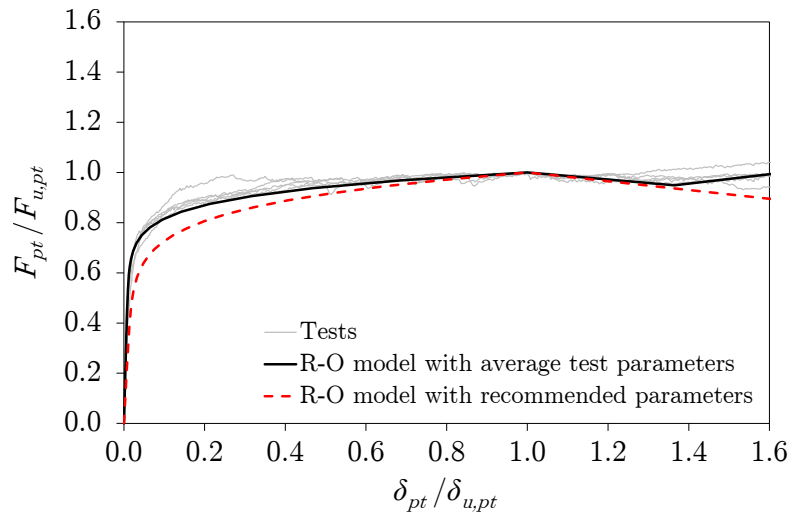

(c) PT-55-2P, detail of the first peak

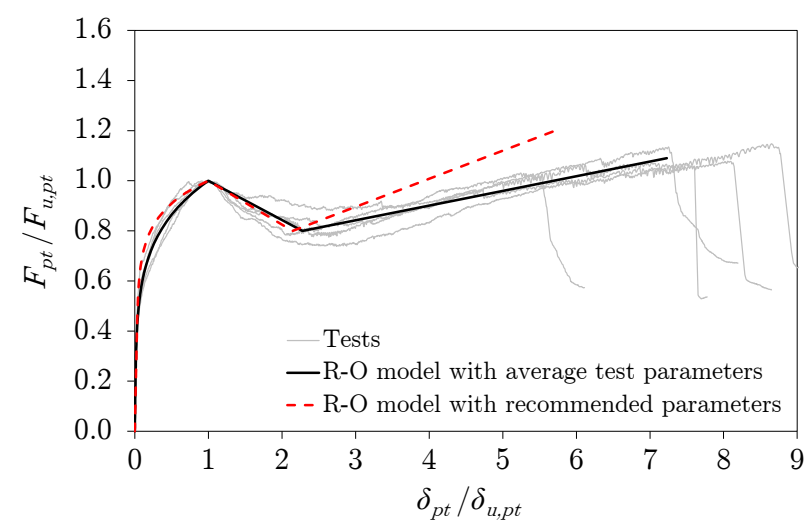

(b) PT-35-2P, overall range

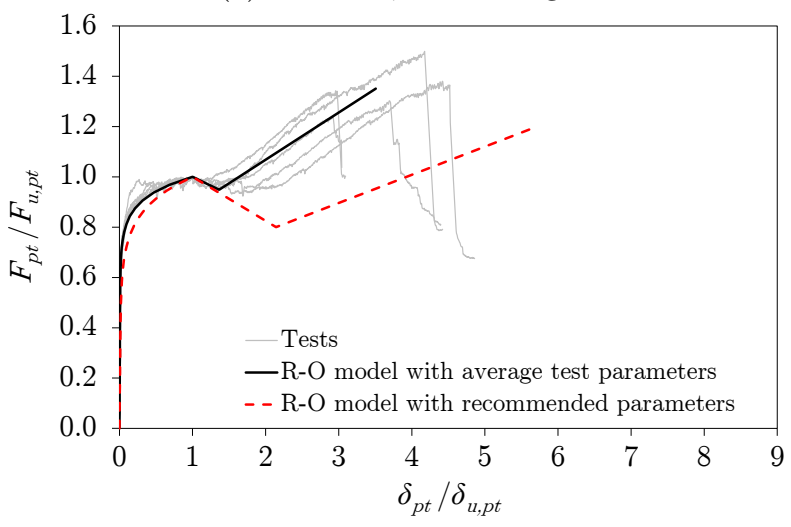

(d) PT-55-2P, overall range

Figure 11: Comparisons of the proposed model using test and recommended predicted input parameters with test curves for double-board specimens

The derived model curves for all five test groups using the average measured values of the key input parameters provided in Table 5 are plotted together in Figure 12 for comparison. The curves emphasize the superior performance of the steel-to-OSB screwed connections in pull-through, with up to three times the capacity of their plasterboard counterparts. Substantially improved ductility can also be observed when two layers of plasterboard are used in place of a single layer. 


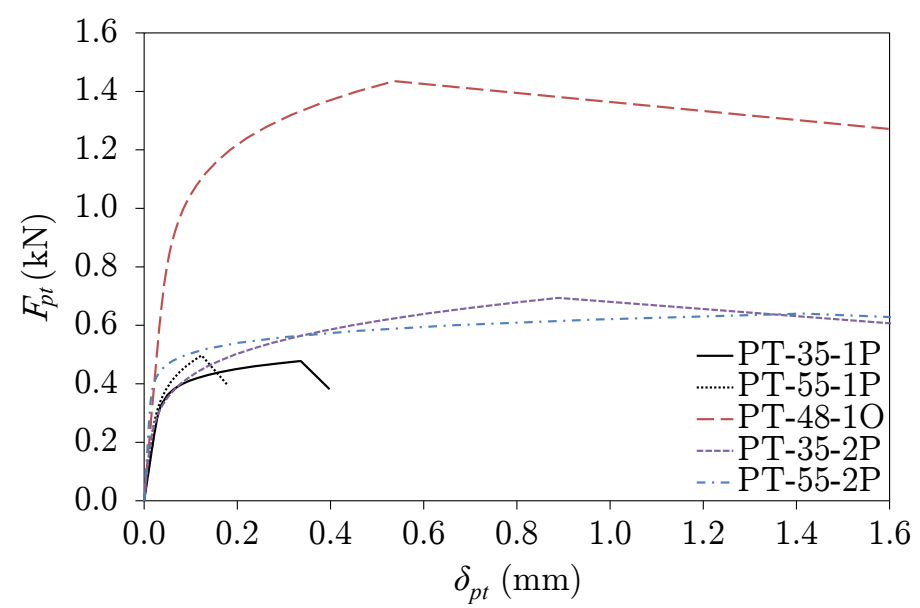

Figure 12: Pull-through load-deformation curves from proposed model for different test groups

\subsection{Shear load-slip response}

The shear load-slip response at the stud-to-sheathing interface, which is controlled by the characteristics of the employed shear connection, can have a significant influence on the structural behaviour of the examined systems; its thorough description is therefore essential. An empirical quad-linear model was devised in [8] and [32] to capture the loadslip response at the interface between cold-formed steel and sheathing boards while, in [7, a load-slip relationship for self-drilling screws connecting cold-formed steel beams and woodbased particle boards was proposed, utilising a generalised Ramberg-Osgood curve.

To facilitate the development of a predictive model for the shear load-slip response of screwed connections between cold-formed steel studs and sheathing boards (i.e. plasterboards and OSBs), more than 80 shear tests (including push-out and pull-out tests), from different sources, have been collected [1] and analysed. A summary of the collected dataset is presented in Table 20 of the companion paper [1]. Note that only tests with plasterboard or OSB sheathing under monotonic loading were collected, while tests with board failure due to the connectors being close to the board edge were ignored. The examined connections failed mainly by tilting of the screw and bearing into the sheathing, while bending or shearing of the screws along with some pull-through was observed when more substantial components (i.e. stronger boards and thicker steel) were connected. 


\subsubsection{Shear load-slip model}

Use of a generalised version of the Ramberg-Osgood formulation given by Equation (3), which has been used thus far for modelling the examined responses, was not found to be capable of accurately capturing the shape of some of the test curves over their full range using a single value for the strain hardening exponent $n$. Hence, a generalised RambergOsgood model with two different exponents $n_{i}$ (where $i=1$ or 2 ) for describing the degree of roundedness of the early part and later part of the shear load-slip behaviour is recommended, as given by Equation (15) and illustrated in Figure 13.

$$
\delta_{p o}=\frac{F_{p o}}{K_{o}}+\left(\delta_{x, p o}-\frac{F_{x, p o}}{K_{o}}\right)\left(\frac{F_{p o}}{F_{x, p o}}\right)^{n_{i}}
$$

245

\section{when} companion paper [1], $F_{x, p o}$ is the load at a slip of $\delta_{x, p o}$ and $F_{u, p o}$ is the ultimate load at the corresponding ultimate displacement $\delta_{u, p o}$.

For the initial part of the curve, when $F_{p o} \leq F_{x, p o}$, the first exponent is used i.e. $n_{i}=n_{1}$, while for the later part of the curve when $F_{x, p o}<F_{p o} \leq F_{u, p o}$ the second exponent is used i.e. $n_{i}=n_{2}$.

Based on the experimental results, a suitable point for the transition between the two curves was found to be at a slip of $1 \mathrm{~mm}$ i.e. $\delta_{x, p o}=1 \mathrm{~mm}$ (denoted $\delta_{1, p o}$ ), with the corresponding load denoted $F_{1, p o}$. Values of $n_{1}$ are explored in Section 4.2 .3 with reference to the experimental data, while $n_{2}$ can be expressed by Equation (16), by forcing the curve to pass through the ultimate point $\left(\delta_{u, p o}, F_{u, p o}\right)$.

$$
n_{2}=\frac{\ln \left(\delta_{u, p o}-\frac{F_{u, p o}}{K_{o}}\right)-\ln \left(\delta_{x, p o}-\frac{F_{x, p o}}{K_{o}}\right)}{\ln \left(\frac{F_{u, p o}}{F_{x, p o}}\right)}
$$




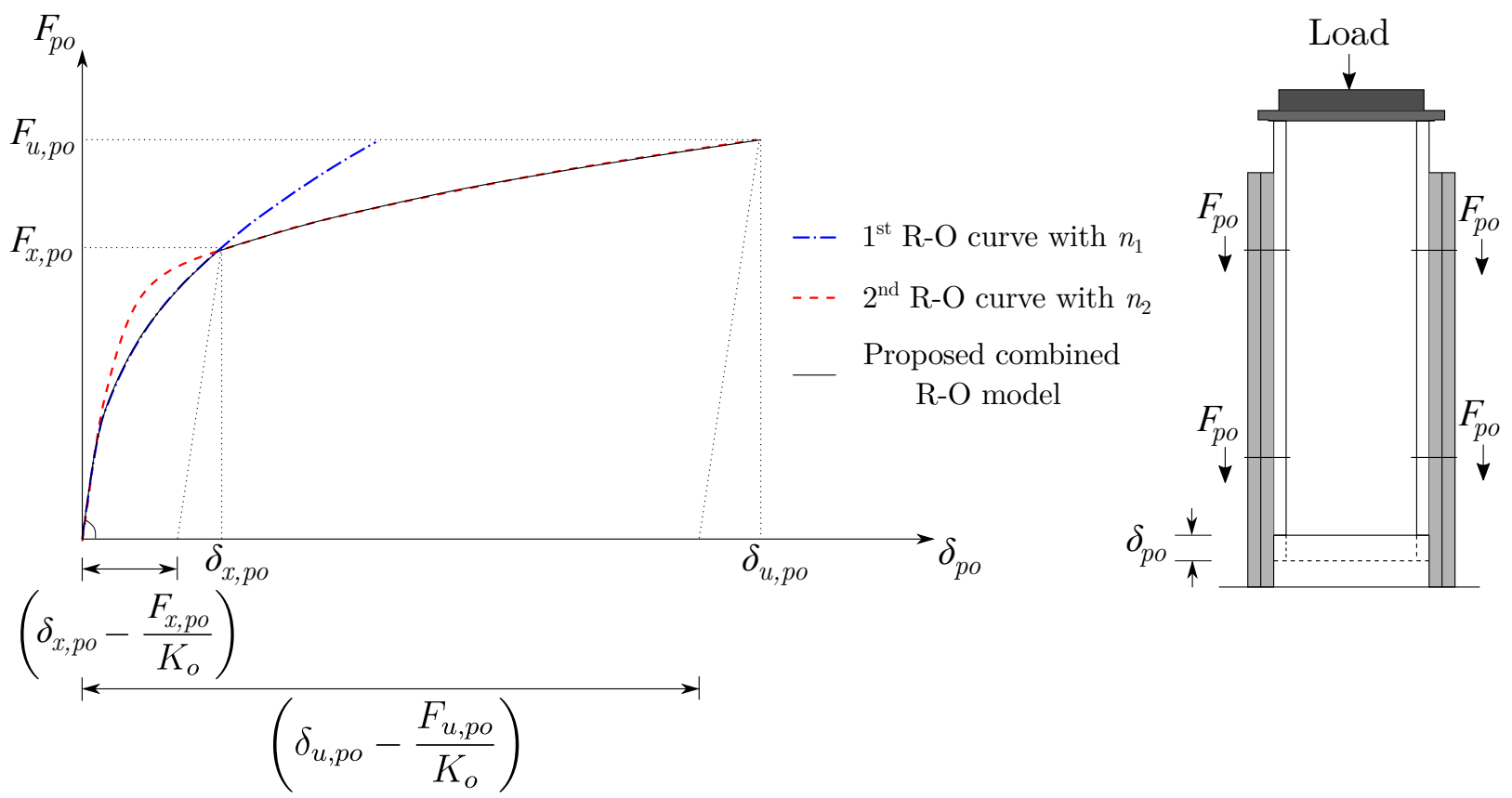

Figure 13: Proposed combined Ramberg-Osgood model consisting of two single Ramberg-Osgood curves for describing the shear load-slip behaviour of screw connections between cold-formed steel and sheathing

\subsubsection{Calculation of key parameters for shear load-slip model}

Expressions for the prediction of the load carrying capacity per shear plane of a screw connector in a steel-to-timber connection, as provided in EN 1995-1-1 [33], are presented and assessed herein for the prediction of $F_{u, p o}$ - see Equations (17) and (19). According to EN 1995-1-1 [33], the failure mode of a connector is dependent on the thickness of the steel section to which the sheathing is attached. A steel section with thickness less than half the nominal diameter of the screw (i.e. $t_{s}<0.5 d$ ) is classified as thin and the associated modes of failure are tilting and bending of the screw in the board; these failure modes are illustrated in Figures 14 (a) and (b) respectively, while the corresponding predictions of $F_{u, p o}$ are given by Equation (17).

$$
F_{u, p o}=\min \begin{cases}0.4 f_{h, k} t_{b} d & \text { (for Mode a) } \\ 1.15 \sqrt{2 M_{y, \text { screw }} f_{h, k} d}+\frac{F_{u, p t}}{4} & \text { (for Mode b) }\end{cases}
$$

where $f_{h, k}$ is the embedment strength in $\mathrm{N} / \mathrm{mm}^{2}$ of the board material, $t_{b}$ is the thickness of the board, $d$ is the diameter of the screw, $F_{u, p t}$ is the pull-through (withdrawal) capacity 
of the fastener, which can be calculated using Equation (8) in the absence of experimental data and $M_{y, \text { screw }}$ is the yield moment of the screw given by Equation (18).

$$
M_{y, \text { screw }}=f_{y} d_{s, s h}^{3} / 6
$$

where $f_{y}$ is the yield strength of the screw and $d_{s, s h}$ - the diameter of the shank of the screw, which is approximately 0.75 times the nominal screw diameter $d$.

A steel plate is classified as thick when its thickness is greater than or equal to the diameter $d$ of the screw; the associated modes of failure, shown in Figures 14 (c), (d) and (e), are bearing and single and double bending of the screw, respectively, while the corresponding predictions of $F_{u, p o}$ are given by Equation (19).

$$
F_{u, p o}=\min \begin{cases}f_{h, k} t_{b} d & (\text { for Mode c) } \\ f_{h, k} t_{b} d\left(\sqrt{2+\frac{4 M_{y, s c r e w}}{f_{h, k} d t_{b}^{2}}}-1\right)+\frac{F_{u, p t}}{4} & (\text { for Mode d) } \\ 2.3 \sqrt{M_{y, \text { screw }} f_{h, k} d}+\frac{F_{u, p t}}{4} & \text { (for Mode e) }\end{cases}
$$

In accordance to to EN 1995-1-1 [33], for the capacity of connections $F_{u, p o}$ with steel plates between a thin and a thick steel plate, linear interpolation between the limiting thin and thick plate values may be carried out.

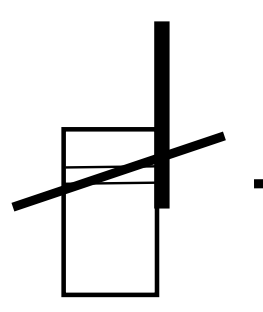

(a)

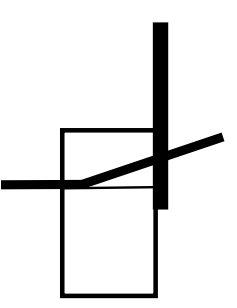

(b)

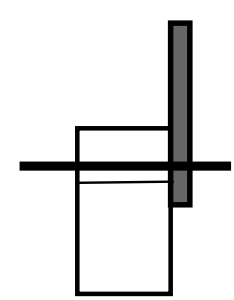

(c)

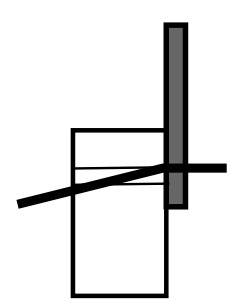

(d)

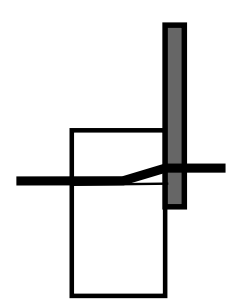

(e)

Figure 14: Failure modes for steel-to-timber connections in accordance with EN 1995-1-1 33]: (a) tilting, (b) bending in board, (c) bearing, (d) bending at steel plate and (e) double bending

Use of Equation (20) is recommended by EN 1995-1-1 [33] for the calculation of the embedment strength of timber $f_{h, k, g e n}$, expressed as a function of the board density $\rho_{k}$, while, specifically for OSB, use of Equation 21) is recommended for the calculation of embedment 
strength $f_{h, k, O S B}$ [33]. Note that, although Equations (20) and 21) were initially developed for nails, they can be also employed for screws by taking their effective diameter $d_{\text {eff }}$ equal to the shank diameter $d_{s, s h}$ [33].

$$
\begin{aligned}
& f_{h, k, g e n}=0.082 \rho_{k} d_{e f f}^{-0.3} \\
& f_{h, k, O S B}=65 d_{e f f}^{-0.7} t_{b}^{0.1}
\end{aligned}
$$

Since there is no expression for the embedment strength of plasterboard in EN 520 [34], Equation (22), which is analogous to Equation (21), was devised based on the collected dataset (of 47 tests) summarised in Table 20 of the companion paper [1]. Equation 22] was defined in terms of the effective diameter $d_{e f f}$ (i.e. the screw shank diameter $d_{s, s h}$ ), board thickness $t_{b}$ and steel thickness $t_{s}$ with the coefficients determined by means of least squares regression analysis.

$$
f_{h, k, g y p}=83 d_{e f f}^{-0.2} t_{b}^{-0.3} t_{s}^{-0.2}
$$

According to EN 1995-1-1 [33], none of the specimens from within the examined dataset (summarised in Table 20 of the companion paper [1]) is classified as having thick steel plates and hence the predominant failure modes, corroborated by the conducted experiments, are screw tilting and bending. Note though that some of the specimens fall in the range between $0.5 d$ and $d$ (i.e. between thin and thick steel plate); this is considered to be the reason for multiple failure modes taking place at different stages during these tests, i.e. both tilting (thin plate) and bearing (thick plate) and bending of the screw (thin and thick plate) - or a combination of these - as reported in [1]. All five failure modes illustrated in Figure 14 were therefore represented in the test data. In assessing the accuracy of the predictive equations for $F_{u, p o}$ (i.e. Equations (17) and (19), the measured values of the screw yield strength $f_{y}$ were used for the tests performed in the companion paper [1] $\left(f_{y}=1020 \mathrm{MPa}\right.$ for the 3.5 mm screws and $f_{y}=730 \mathrm{MPa}$ for the $5.5 \mathrm{~mm}$ screws), while for the other tests reported in literature, which had nominal screw diameters ranging from $3.5 \mathrm{~mm}$ to $4.8 \mathrm{~mm}$, an estimated value of $f_{y}=800 \mathrm{MPa}$ was adopted, based on an analysis of the observed failure modes. The density of plasterboard was taken as $650 \mathrm{~kg} / \mathrm{m}^{3}$ in accordance with measurements in 
[1]. Note though that plasterboard densities vary among manufacturers and with humidity $[1,20,35]$.

\subsubsection{Shear capacity predictions $F_{u, p o}$ for screwed connections in plasterboard}

For the 47 tests on screwed connections in plasterboard [1], comparisons between the test shear capacity values $F_{u, p o, t e s t}$ and the predicted values using Equations (17) and (19) with the generic embedment strength of Equation (20) [33], are presented in Figure 15. The critical failure mode for all cases where $t_{s} / d \leq 0.5$ was Mode a (screw tilting) according to Equation (17). For the ten cases falling into the intermediate thickness range of $0.5<$ $t_{s} / d \leq 1.0$, the capacity prediction $F_{u, p o}$ required interpolation between the critical results for thin plates (Equation (17)) and thick plates (Equation (19)), which were for Mode a and Mode d (i.e. screw bending in thick plates with pull-through) respectively. The predominant mode of failure from the tests was screw tilting and therefore largely in agreement with the predictions of Eurocode 5. Despite plasterboard not being explicitly covered by Eurocode 5, Equation (17) provides good predictions of the test results, though further improvements remain possible.

In Figure 16, a comparison between the $F_{u, p o, t e s t}$ values and $F_{u, p o}$ predictions obtained using Equation (17) up to an extended limit for the thin plates of $t_{s} / d \leq 0.75$, with the embedment strength calculated using Equation (20) and the newly proposed Equation (22), is provided. As apparent from the results, including the mean values and coefficients of variation shown in Figures 16 (a) and (b) and Table 6, use of Equation 22) for the calculation of the embedment strength, when plasterboard is used, provides a more accurate estimation of $F_{u, p o}$ with reduced scatter. Hence, use of Equation (17) up to an extended limit for thin plates of $t_{s} / d \leq 0.75$, along with Equation (22), is recommended for screwed connections in plasterboard within the range of properties examined herein. 


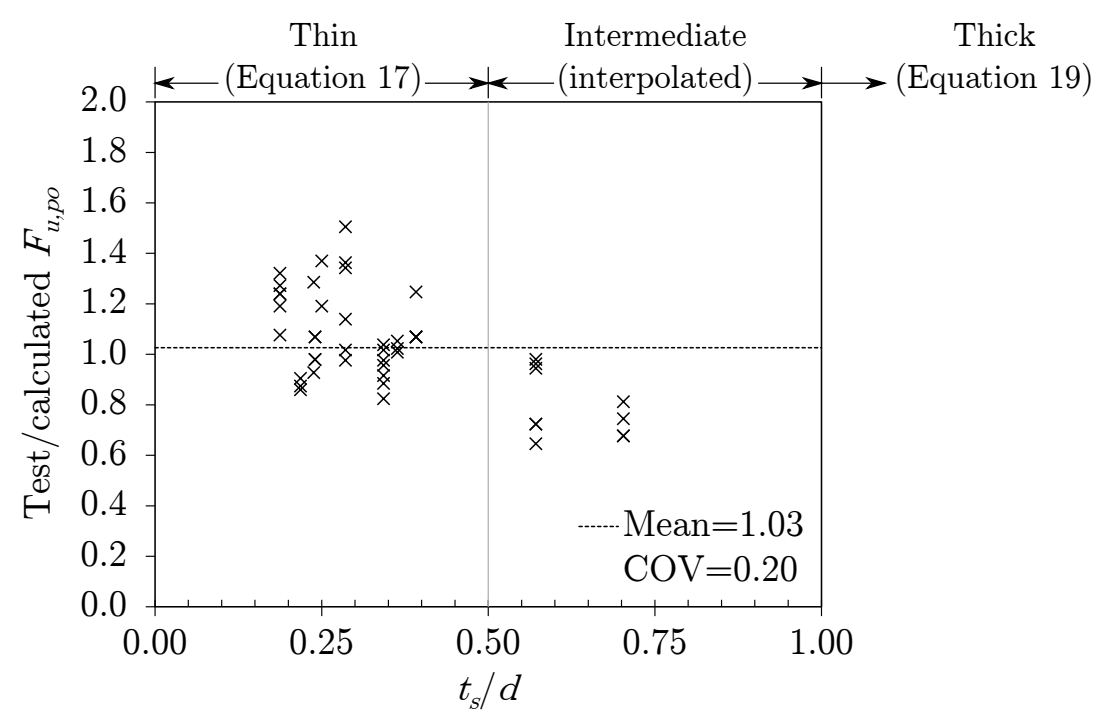

Figure 15: Comparisons between test and predicted $F_{u, p o}$ values for all screwed connections in plasterboard, calculated using Eurocode 5 [33], with Equation (20) for embedment strength and interpolation between critical values from Equations (17) and 119 ) for cases when $0.5<t_{s} / d \leq 1.0$

Thin

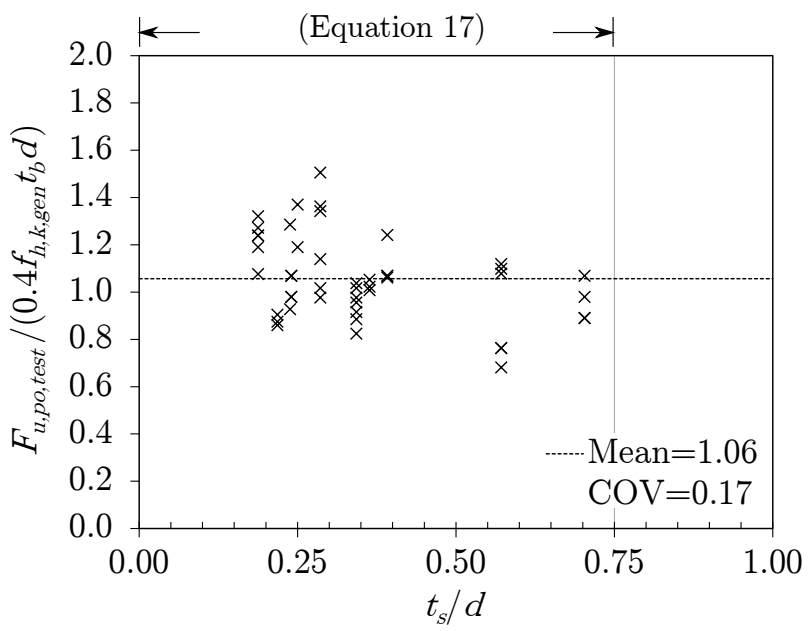

(a) Tilting with $f_{h, k, g e n}$
Thin

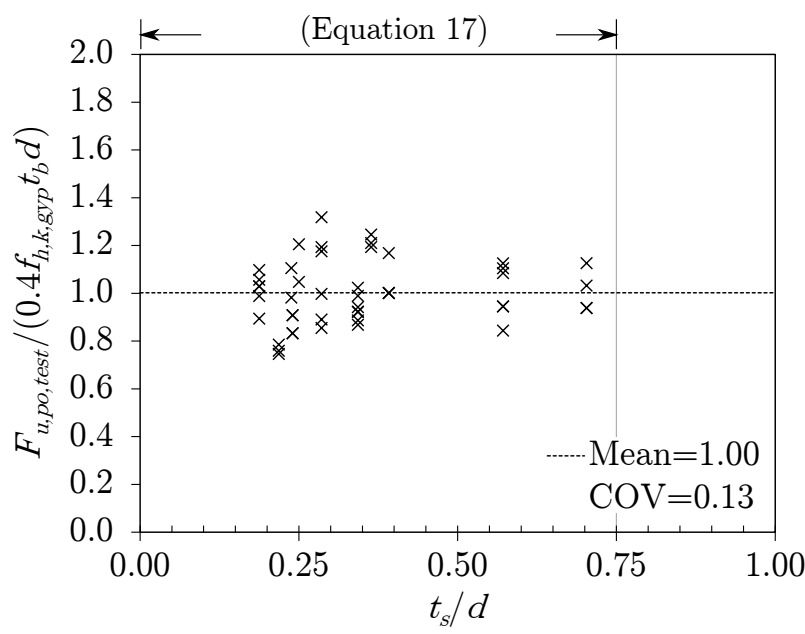

(b) Tilting with $f_{h, k, g y p}$

Figure 16: Comparisons between test and predicted $F_{u, p o}$ values calculated using Equation (17) Mode a (screw tilting) with embedment strength (a) $f_{h, k, g e n}$ (Equation (20) ) and (b) $f_{h, k, g y p}$ (Equation (22) for all screwed connections in plasterboard with the thin plate limit extended to $t_{s} / d \leq 0.75$ 
Table 6: Comparisons between predictions of $F_{u, p o}$ for shear tests with plasterboard using Equation (17) for Mode a (tilting) with embedment strength calculated using Equations (20) and 22)

\begin{tabular}{|c|c|c|c|c|c|c|c|c|}
\hline \multirow[t]{2}{*}{ Sheathing } & \multirow[t]{2}{*}{$t_{b}(\mathrm{~mm})$} & \multirow[t]{2}{*}{$t_{s}(\mathrm{~mm})$} & \multirow[t]{2}{*}{$d(\mathrm{~mm})$} & \multirow[t]{2}{*}{ No. of tests } & \multicolumn{2}{|c|}{$\frac{F_{u, p o, t e s t}}{0.4 f_{h, k, g e n} t_{b} d}$} & \multicolumn{2}{|c|}{$\frac{F_{u, p o, t e s t}}{0.4 f_{h, k, g y p} t_{b} d}$} \\
\hline & & & & & Mean & $\mathrm{COV}$ & Mean & $\mathrm{COV}$ \\
\hline \multirow{10}{*}{ Plasterboard } & 12.5 & $0.8-2.0$ & 3.5 & 21 & 1.10 & 0.13 & 1.00 & 0.14 \\
\hline & 12.5 & 2.5 & 3.5 & 4 & 0.96 & 0.09 & 1.01 & 0.09 \\
\hline & 12.5 & 1.0 & 4.2 & 1 & 1.29 & - & 1.11 & - \\
\hline & 12.5 & $0.9-1.2$ & 4.8 & 8 & 1.24 & 0.07 & 1.04 & 0.08 \\
\hline & 12.5 & 1.2 & 5.5 & 3 & 0.88 & 0.03 & 0.76 & 0.03 \\
\hline & $2 \times 12.5$ & 1.2 & 3.5 & 3 & 0.87 & 0.05 & 0.98 & 0.05 \\
\hline & $2 \times 12.5$ & 1.0 & 4.2 & 1 & 0.93 & - & 0.98 & - \\
\hline & $2 \times 12.5$ & 2.0 & 3.5 & 3 & 0.74 & 0.06 & 0.91 & 0.06 \\
\hline & $2 \times 12.5$ & 2.0 & 5.5 & 3 & 1.03 & 0.02 & 1.22 & 0.02 \\
\hline & & & & Overall & 1.06 & 0.17 & 1.00 & 0.13 \\
\hline
\end{tabular}

\subsubsection{Shear capacity predictions $F_{u, p o}$ for screwed connections in OSB}

For the 39 tests on screwed connections in OSB [1], comparisons between the test shear capacity values and the predicted values $F_{u, p o}$ using Equations (17) and (19) with the OSB embedment strength given by Equation (21) [33], are presented in Figure 17. According to Equation (17), the critical failure mode for specimens with $t_{s} / d \leq 0.5$ was Mode a (tilting) in all cases, but the resulting resistance predictions can be seen from Figure 17 to be poor. Moreover, the predicted failure mode did not accord well with those observed in the physical experiments, where bending [32] and pull-through [36 38] failures were reported. Therefore, in Figure 18 and Table 7 comparisons are made between the $F_{u, p o}$ test values and the $F_{u, p o}$ predictions considering Mode b (i.e. bending and pull-through) in Equation (17) for the cases when $t_{s} / d \leq 0.5$. For the five specimens that fall marginally beyond the thin plate category, into the intermediate category, linear interpolation between Mode $\mathrm{b}$ in Equation (17) and the Mode d in Equation (19) was performed. The comparisons reveal that good 
predictions of the test results (both in terms of capacity and failure mode) are achieved using the Mode b resistance equation; use of Equation (23) is therefore recommended for screwed connections in OSB and not the minimum between the resistances for Modes a and b from Equation (17], as recommended by EN 1995-1-1 [33]), for cases when $t_{s} / d \leq 0.5$. For cases when $0.5<t_{s} / d \leq 1.0$, interpolation between Equation 23 and the critical value from Equation (19) is recommended.

$$
F_{u, p o}=1.15 \sqrt{2 M_{y, s c r e w} f_{h, k, O S B} d}+F_{u, p t} / 4
$$

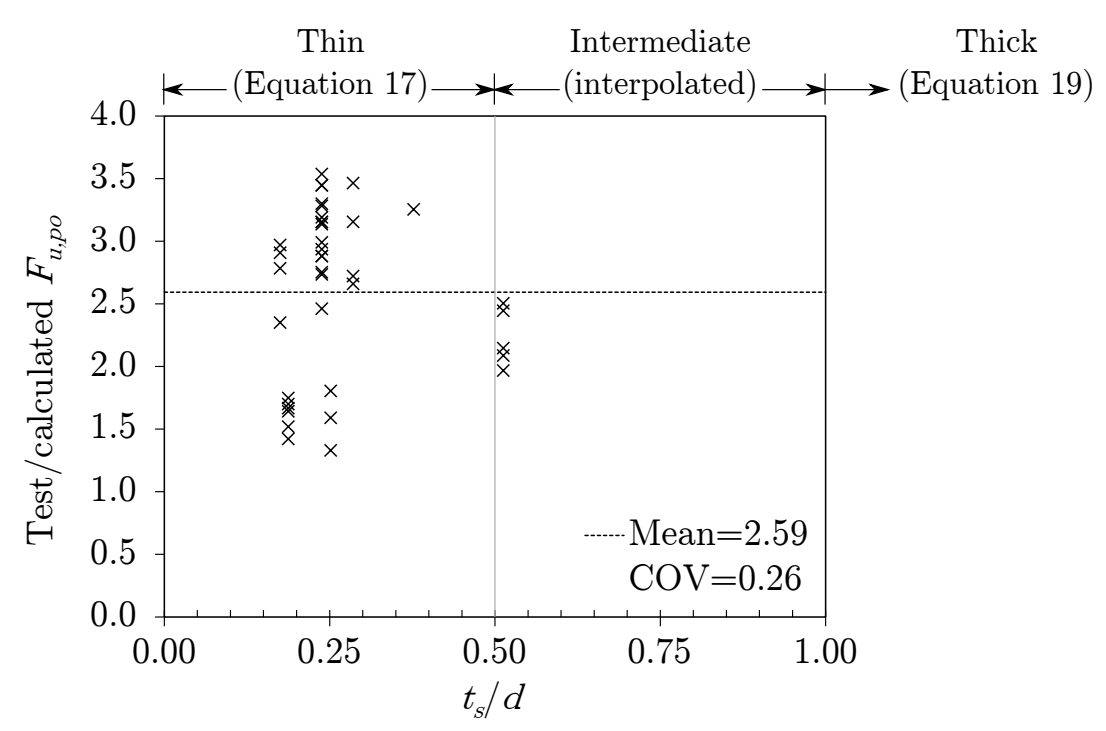

Figure 17: Comparisons between test and predicted $F_{u, p o}$ values for all screwed connections in OSB, calculated using Eurocode 5 [33], with Equation (21) for embedment strength and interpolation between the critical values from Equations (17) and 19 for cases when $0.5<t_{s} / d \leq 1.0$ 


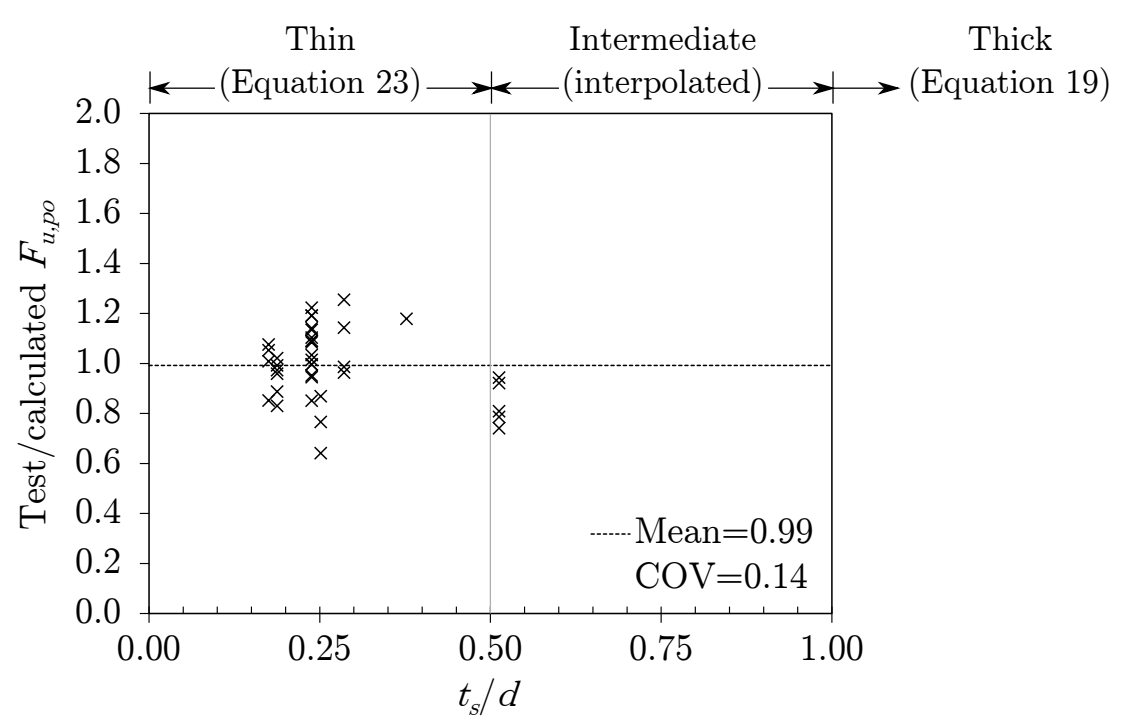

Figure 18: Comparisons between test and predicted $F_{u, p o}$ values for all screwed connections in OSB, calculated using Equation (23) for cases $t_{s} / d \leq 0.5$ and interpolation between Equation (23) and the critical value from Equation 19 for cases when $0.5<t_{s} / d \leq 1.0$

Table 7: Comparisons between test and predicted $F_{u, p o}$ values for groups of screwed connections in OSB with similar characteristics, calculated using Equation 23 for cases $t_{s} / d \leq 0.5$ and interpolation between Equation 23 and the critical value of Equation (19) for cases when $0.5<t_{s} / d \leq 1.0$

\begin{tabular}{cccccccc}
\hline Sheathing & $t_{b}(\mathrm{~mm})$ & $t_{s}(\mathrm{~mm})$ & $d(\mathrm{~mm})$ & No. of tests & \multicolumn{2}{c}{$\frac{F_{u, p o, \text { test }}}{F_{u, p o}}$} & $F_{u, p o}$ calculated using \\
& & & & Mean & COV & \\
\hline \multirow{4}{*}{ OSB } & 11.1 & 0.9 & 3.5 & 3 & 0.76 & 0.15 & Equation [23] \\
& 9.0 & 1.0 & 4.2 & 16 & 1.06 & 0.10 & Equation [23] \\
& 18 & 0.9 & 4.8 & 6 & 0.94 & 0.08 & Equation [23] \\
& 11.1 & $0.8-1.4$ & 4.8 & 9 & 1.06 & 0.12 & Equation [23] \\
\hline & 11.1 & 2.5 & 4.8 & 5 & 0.84 & 0.10 & Interpolation between Eqs. [23] and [19] \\
\hline
\end{tabular}

\subsubsection{3. $K_{o}, \delta_{u, p o}$ and $F_{1, p o}$ estimations}

Recommended values for the remainder of the input parameters for the proposed model of Equations (15) and (16), namely the initial stiffness $K_{o}$ and the ultimate displacement $\delta_{u, p o}$ are provided in Table 8; these have been determined as the average values from groups 
of data with similar characteristics in terms of the embedment strength $f_{h, k}$ and screw diameter $d$. Embedment strength was calculated using Equation 20 for screw connections in plasterboard and using Equation (21) for screw connections in OSB. The force $F_{1, p o}$ at 1 $\mathrm{mm}$ slip is also provided, expressed as a proportion of the ultimate test capacity $F_{u, p o}$.

From Table 8, it can be seen that the properties are somewhat variable, but the average $K_{o} /\left(f_{h, k} d\right)$ values are approximately 10 for both plasterboard and OSB. For ultimate displacement $\delta_{u, p o}$, the values typically range between $0.75 d$ and $3.0 d$ for the plasterboard specimens and between $0.5 d$ and $1.75 d$ for the OSB specimens.

Table 8: Average measured values for key properties derived from full load-slip $F_{p o}-\delta_{p o}$ curves obtained from shear tests, grouped by common arrangement properties

\begin{tabular}{|c|c|c|c|c|c|c|c|c|c|c|}
\hline \multirow[t]{2}{*}{ Sheathing } & \multirow[t]{2}{*}{$t_{b}(\mathrm{~mm})$} & \multirow[t]{2}{*}{$t_{s}(\mathrm{~mm})$} & \multirow[t]{2}{*}{$d(\mathrm{~mm})$} & \multirow{2}{*}{$\begin{array}{c}\text { Full } F-\delta \\
\text { curves }\end{array}$} & \multicolumn{2}{|c|}{$\frac{K_{o}}{f_{h, k} d}$} & \multicolumn{2}{|c|}{$\delta_{u, p o} / d$} & \multicolumn{2}{|c|}{$F_{1, p o} / F_{u, p o}$} \\
\hline & & & & & Mean & $\mathrm{COV}$ & Mean & $\mathrm{COV}$ & Mean & $\mathrm{COV}$ \\
\hline \multirow{8}{*}{ Plasterboard } & 12.5 & $0.8-2.0$ & 3.5 & 16 & 14.08 & 0.81 & 2.06 & 0.39 & 0.71 & 0.09 \\
\hline & 12.5 & 2.5 & 3.5 & 4 & 11.01 & 0.19 & 1.20 & 0.68 & 0.96 & 0.07 \\
\hline & 12.5 & $0.9-1.2$ & 4.8 & 4 & 5.57 & 0.13 & 0.77 & 0.26 & 0.56 & 0.09 \\
\hline & 12.5 & 1.2 & 5.5 & 3 & 6.69 & 0.05 & 1.00 & 0.13 & 0.76 & 0.01 \\
\hline & $2 \times 12.5$ & 1.2 & 3.5 & 3 & 25.7 & 0.25 & 3.36 & 0.03 & 0.44 & 0.06 \\
\hline & $2 \times 12.5$ & 2.0 & 3.5 & 3 & 12.68 & 0.18 & 1.54 & 0.12 & 0.53 & 0.05 \\
\hline & $2 \times 12.5$ & 2.0 & 5.5 & 3 & 4.68 & 0.07 & 2.12 & 0.03 & 0.36 & 0.04 \\
\hline & & & & Overall & 12.25 & 0.77 & 1.67 & 0.56 & 0.67 & 0.26 \\
\hline \multirow{5}{*}{ OSB } & 9.0 & 1.0 & 4.2 & 4 & 14.84 & 0.16 & 1.33 & 0.23 & 0.55 & 0.20 \\
\hline & 18 & 0.9 & 4.8 & 4 & 3.69 & 0.29 & 1.73 & 0.24 & 0.28 & 0.22 \\
\hline & 11.1 & $0.8-1.4$ & 4.8 & 9 & 10.45 & 0.19 & 1.52 & 0.15 & 0.51 & 0.17 \\
\hline & 11.1 & 2.5 & 4.8 & 4 & 14.39 & 0.08 & 0.52 & 0.23 & 0.86 & 0.09 \\
\hline & & & & Overall & 10.75 & 0.40 & 1.33 & 0.34 & 0.54 & 0.38 \\
\hline
\end{tabular}

\subsubsection{Assessment of proposed shear model against experimental data}

Typical comparisons between the proposed load-slip model and the respective experimental curves for the single- and double-layer plasterboard specimens, as well as for the OSB specimens, are presented in Figures 19,20 and 21 respectively, where the load $F_{p o}$ normalised 
by the ultimate load $F_{u, p o}$ is plotted against the slip at the shear interface $\delta_{p o}$ normalised by the ultimate slip $\delta_{u, p o}$. It can be observed that the devised expression provides a good fit to the experimental data and is therefore suitable for use in numerical simulations and advanced design methods. The average values of the key parameters used as input for the curves presented in Figures 19, 20 and 21 are provided in Table 9. Note that, the exponent $n_{1}$ used to define the degree of roundedness of the initial part of the curves (i.e. below a slip of $1 \mathrm{~mm}$ ) was found to be within the range of 3.4 - 3.6 when the board connected was a single layer of either plasterboard or OSB, while for specimens with two layers of plasterboard, a value of $n_{1}=2$ was shown to provide a better fit to the respective test curves.

Table 9: Average values of the parameters required as input for the proposed models $\left(t_{b}\right.$ - board thickness, $t_{s}$ - steel thickness, $d$ - screw diameter)

\begin{tabular}{|c|c|c|c|c|c|c|c|c|c|c|}
\hline Sheathing & $\begin{array}{c}t_{b} \\
(\mathrm{~mm})\end{array}$ & $\begin{array}{c}t_{s} \\
(\mathrm{~mm})\end{array}$ & $\begin{array}{c}d \\
(\mathrm{~mm})\end{array}$ & $\begin{array}{c}\text { Full } F-\delta \\
\text { curves }\end{array}$ & & $\begin{array}{c}K_{o} \\
(\mathrm{kN} / \mathrm{mm})\end{array}$ & $\begin{array}{l}F_{u, p o} \\
(\mathrm{kN})\end{array}$ & $\begin{array}{c}\delta_{u, p o} \\
(\mathrm{~mm})\end{array}$ & $\begin{array}{l}F_{1, p o} \\
(\mathrm{kN})\end{array}$ & $n_{1}$ \\
\hline \multirow{8}{*}{ Plasterboard } & \multirow{2}{*}{12.5} & \multirow{2}{*}{$0.8-2.5$} & \multirow{2}{*}{$3.5-5.5$} & \multirow{2}{*}{28} & Mean & 1.26 & 0.58 & 6.29 & 0.42 & 3.4 \\
\hline & & & & & $\mathrm{COV}$ & 0.70 & 0.19 & 0.48 & 0.20 & 0.09 \\
\hline & \multirow{2}{*}{12.5} & \multirow{2}{*}{$0.8-2.5$} & \multirow{2}{*}{$3.5-5.5$} & \multirow{2}{*}{23} & Mean & 1.34 & 0.54 & 6.93 & 0.41 & 3.4 \\
\hline & & & & & $\mathrm{COV}$ & 0.71 & 0.13 & 0.42 & 0.19 & 0.10 \\
\hline & \multirow{2}{*}{12.5} & \multirow{2}{*}{$0.9-1.0$} & \multirow{2}{*}{$4.2-4.8$} & \multirow{2}{*}{5} & Mean & 0.87 & 0.77 & 3.35 & 0.48 & 3.5 \\
\hline & & & & & $\mathrm{COV}$ & 0.70 & 0.19 & 0.48 & 0.20 & 0.09 \\
\hline & \multirow{2}{*}{$2 \times 12.5$} & \multirow{2}{*}{$1.0-2.0$} & \multirow{2}{*}{$3.5-5.5$} & \multirow{2}{*}{10} & Mean & 1.26 & 0.99 & 8.98 & 0.47 & 2.0 \\
\hline & & & & & $\mathrm{COV}$ & 0.62 & 0.29 & 0.45 & 0.34 & 0.19 \\
\hline \multirow{2}{*}{ OSB } & \multirow{2}{*}{$9-18$} & \multirow{2}{*}{$0.8-2.5$} & \multirow{2}{*}{$4.2-4.8$} & \multirow{2}{*}{21} & Mean & 1.72 & 1.90 & 5.94 & 1.00 & 3.6 \\
\hline & & & & & $\mathrm{COV}$ & 0.39 & 0.15 & 0.43 & 0.31 & 0.06 \\
\hline
\end{tabular}




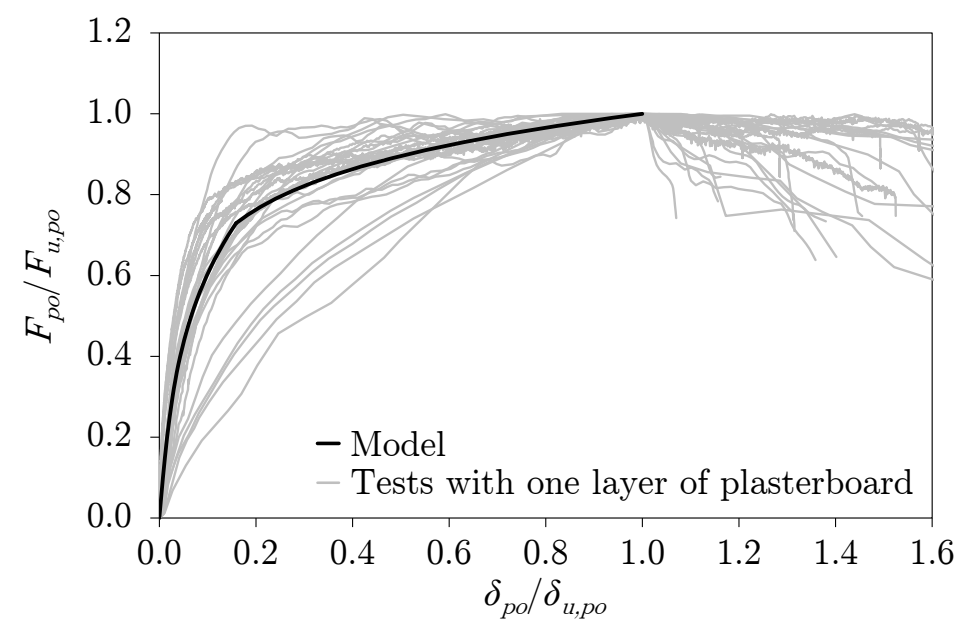

Figure 19: Comparison between the proposed load-slip model and normalised test curves for specimens with one layer of plasterboard

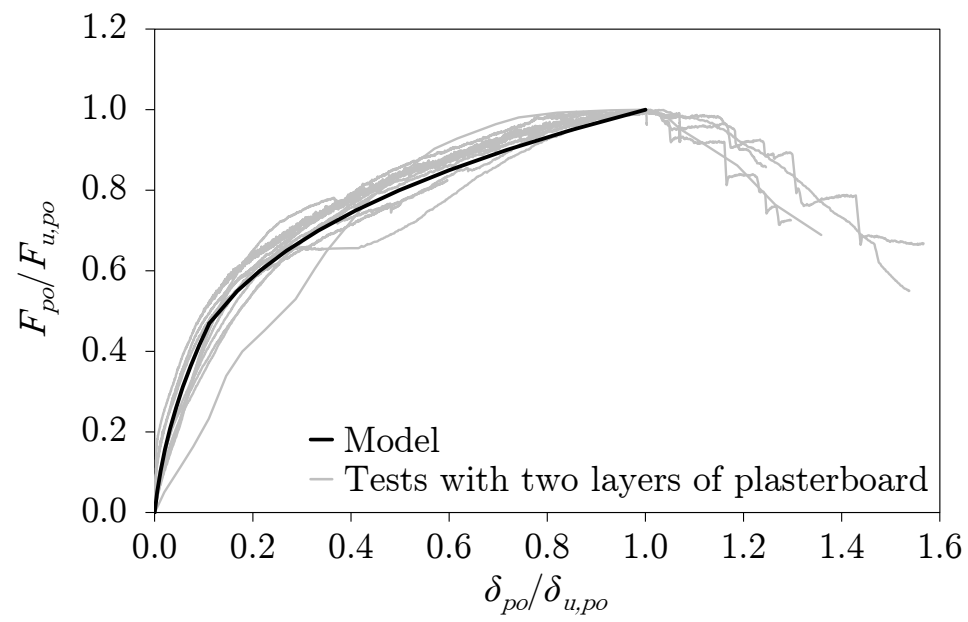

Figure 20: Comparison between the proposed load-slip model and normalised test curves for specimens with two layers of plasterboard 


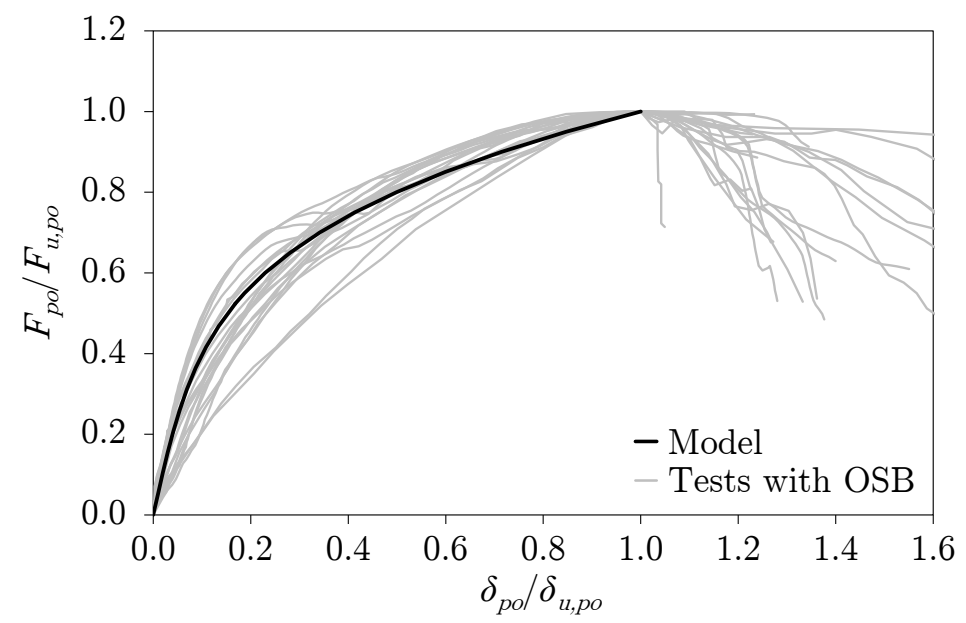

Figure 21: Comparison between the proposed load-slip model and normalised test curves for specimens with OSB

The average measured values of the key properties of screw connectors per shear plane for different steel-to-sheathing connections is provided in Table 10 , while the associated twopart Ramberg-Osgood model curves for each type of connection are presented in Figure 22 . The designation system employed for the specimens with plasterboard starts with $1 \mathrm{P}$ or $2 \mathrm{P}$ to indicate one or two layers of plasterboard (with the thickness of each layer ranging between 12.5 and $12.7 \mathrm{~mm}$ ), while for the OSB specimens, the designation starts with $\mathrm{O}$ and is followed by the board thickness in mm. For all specimens, the designation name is completed by the nominal diameter of the screw in mm multiplied by 10 and finally by the thickness of the steel section to which the fixing is connected, with 'th' denoting a thin plate (of thickness less than half of the screw diameter) and 'm' a medium thickness plate (in the range of $d / 2-d)$. The curves shown in Figure 22, emphasize the greater ductility obtained when using two layers of plasterboard compared to a single layer and the higher shear resistances achieved by the OSB specimens in comparison to the plasterboard specimens. 
Table 10: Average measured values of key properties of screw connectors per shear plane for different steel-to-sheathing connections $\left(t_{b}\right.$ - board thickness, $t_{s}$ - steel thickness, $d$ - screw diameter)

\begin{tabular}{|c|c|c|c|c|c|c|c|c|c|}
\hline Designation & Sheathing & $\begin{array}{c}t_{b} \\
(\mathrm{~mm})\end{array}$ & $\begin{array}{c}t_{s} \\
(\mathrm{~mm})\end{array}$ & $\begin{array}{c}d \\
(\mathrm{~mm})\end{array}$ & $\begin{array}{l}F_{u, p o} \\
(\mathrm{kN})\end{array}$ & $\begin{array}{c}K_{o} \\
(\mathrm{kN} / \mathrm{mm})\end{array}$ & $\begin{array}{c}\delta_{u, p o} \\
(\mathrm{~mm})\end{array}$ & $\begin{array}{l}F_{1, p o} \\
(\mathrm{kN})\end{array}$ & $n_{1}$ \\
\hline 1P-35-th & \multirow{7}{*}{ Plasterboard } & 12.5 & $0.8-2.0$ & 3.5 & 0.55 & 1.47 & 7.22 & 0.39 & 3.3 \\
\hline 1P-35-m & & 12.5 & 2.5 & 3.5 & 0.48 & 1.03 & 4.19 & 0.46 & 3.6 \\
\hline 1P-48-th & & 12.5 & $0.9-1.2$ & 4.8 & 0.76 & 0.82 & 3.71 & 0.44 & 3.5 \\
\hline 1P-55-th & & 12.5 & 1.2 & 5.5 & 0.59 & 1.04 & 5.48 & 0.45 & 3.2 \\
\hline 2P-35-th & & $2 \times 12.5$ & 1.2 & 3.5 & 0.86 & 2.26 & 11.8 & 0.38 & 2.3 \\
\hline $2 \mathrm{P}-35-\mathrm{m}$ & & $2 \times 12.5$ & 2.0 & 3.5 & 0.72 & 1.01 & 5.40 & 0.38 & 1.9 \\
\hline $2 \mathrm{P}-55-\mathrm{m}$ & & $2 \times 12.5$ & 2.0 & 5.5 & 1.39 & 0.53 & 11.6 & 0.50 & 1.5 \\
\hline O9-42-th & \multirow{4}{*}{ OSB } & 9.0 & 1.0 & 4.2 & 1.69 & 2.26 & 5.60 & 0.90 & 3.5 \\
\hline O18-48-th & & 18 & 0.9 & 4.8 & 1.98 & 0.63 & 8.29 & 0.55 & 3.5 \\
\hline O11-48-th & & 11.1 & $0.8-1.4$ & 4.8 & 2.10 & 1.69 & 7.29 & 1.06 & 3.6 \\
\hline O11-48-m & & 11.1 & 2.5 & 4.8 & 1.66 & 2.33 & 2.49 & 1.38 & 3.5 \\
\hline
\end{tabular}




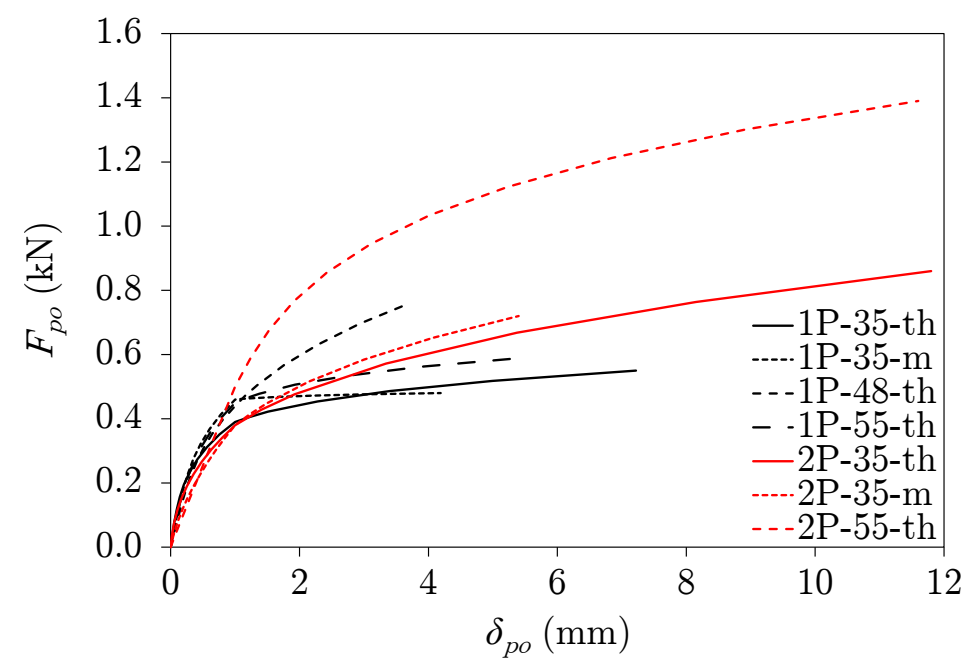

(a) Specimens with plasterboard

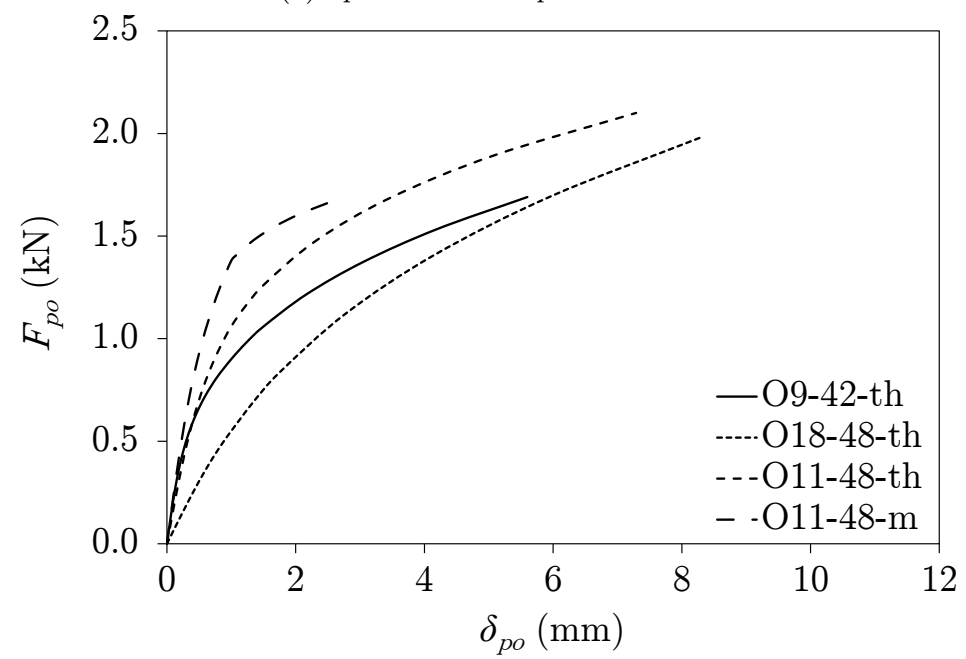

(b) Specimens with OSB

Figure 22: Model fitting of the average key properties presented in Table 10 and comparisons between the load-slip behaviour of a screw connector per shear plane when connected to (a) plasterboard and (b) OSB

\section{Summary of proposals}

Based on the conducted analyses, the proposed expressions to describe the response of the components of cold-formed steel stud wall systems, both at the material and connection levels, are summarised in Table 11. The key input parameters and references are also highlighted. 
Table 11: Summary of models and associated parameters for each material and system interaction system

\begin{tabular}{|c|c|c|c|c|c|c|}
\hline \multirow{2}{*}{ Level } & \multirow{2}{*}{ Type } & \multirow{2}{*}{ Load } & \multicolumn{2}{|c|}{ Model formulation } & \multicolumn{2}{|c|}{ Model parameters } \\
\hline & & & Description & Reference & Parameters & Reference \\
\hline \multirow{8}{*}{ Material } & $\begin{array}{l}\text { Cold-formed steel } \\
\text { (rounded } \sigma-\varepsilon \text { curve) }\end{array}$ & Tension/compression & 2-stage R-O model & $\begin{array}{l}\text { Eqs. 11 and } 2 \\
\text { See } 15\end{array}$ & $\begin{array}{c}E, \sigma_{0.2}, \sigma_{u}, \varepsilon_{u} \\
n, m\end{array}$ & [1], 15] \\
\hline & $\begin{array}{c}\text { Cold-formed steel } \\
(\sigma-\varepsilon \text { curve with plateau })\end{array}$ & Tension/compression & $\begin{array}{l}\text { Quadlinear or bilinear } \\
+ \text { nonlinear model }\end{array}$ & See 19. & $\begin{array}{c}E, \sigma_{0.2}, \varepsilon_{s h}, \\
\sigma_{u}, \varepsilon_{u}\end{array}$ & [1], 19] \\
\hline & \multirow{3}{*}{ Plasterboard } & Tension & $\mathrm{R}-\mathrm{O}$ & Eq. 6] & $E, f_{u}, \varepsilon_{u}, n$ & Table 1 \\
\hline & & \multirow{2}{*}{ Compression } & $\mathrm{R}-\mathrm{O}$ & Eq. 6] & $E, f_{u}, \varepsilon_{u}, n$ & Table 1 \\
\hline & & & Mander & Eqs. 45 and 5 & $E, f_{u}, \varepsilon_{u}$ & Table 1 \\
\hline & \multirow{3}{*}{ OSB } & Tension & $\mathrm{R}-\mathrm{O}$ & Eq. 6] & $E, f_{u}, \varepsilon_{u}, n$ & Table 2 \\
\hline & & Compression & $\mathrm{R}-\mathrm{O}$ & Eq. 6] & $E, f_{u}, \varepsilon_{u}, n$ & Table 2 \\
\hline & & - & Mander & Eqs. 44 and 5 & $E, f_{u}, \varepsilon_{u}$ & Table 2 \\
\hline \multirow{4}{*}{$\begin{array}{l}\text { Component } \\
\text { interaction }\end{array}$} & \multicolumn{2}{|c|}{$\begin{array}{c}\text { Pull-through } \\
\text { (single layer board) }\end{array}$} & $\mathrm{R}-\mathrm{O}+$ linear & Eq. 7] & $\begin{array}{c}K_{o, 40}, F_{u, p t}, \delta_{u, p t}, n \\
F_{u, p t, 0.8}, \delta_{u, p t, 0.8}\end{array}$ & Eqs. 8] - 14], Table 3.44 .5 \\
\hline & \multicolumn{2}{|c|}{$\begin{array}{c}\text { Pull-through } \\
\text { (two layer board) }\end{array}$} & R-O + bilinear & Eq. 7] & $\begin{array}{c}K_{o, 40}, F_{u, p t}, \delta_{u, p t}, n \\
F_{u, p t, 0.8}, \delta_{u, p t, 0.8}, F_{u, p t, 2}, \delta_{u, p t, 2}\end{array}$ & 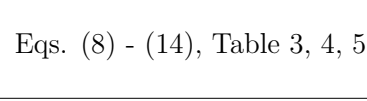 \\
\hline & \multicolumn{2}{|c|}{$\begin{array}{l}\text { Shear with plasterboard } \\
\text { for } t_{s} \leq 0.75 d\end{array}$} & 2 single R-O model & Eqs. 15 and 16 & $K_{o}, F_{u, p o}, \delta_{u, p o}, n_{1}, F_{1, p o}$ & $\begin{array}{c}\text { Eq. } 17 \text {. } \\
\text { Eq. } 22 \text {, Table } 8\end{array}$ \\
\hline & \multicolumn{2}{|c|}{$\begin{array}{l}\text { Shear with OSB } \\
\text { for } t_{s} \leq 0.5 d\end{array}$} & 2 single R-O model & Eqs. 15 and 16 & $K_{o}, F_{u, p o}, \delta_{u, p o}, n_{1}, F_{1, p o}$ & $\begin{array}{l}\text { Eq. 23] - bending (Mode b) } \\
\text { Eqs. 18, 21, Table } 8\end{array}$ \\
\hline
\end{tabular}




\section{Conclusions}

A comprehensive study into the material modelling of the different components forming a typical sheathed cold-formed steel wall system, as well as into the behaviour of the employed connectors in pull-through and shear has been presented. An experimental dataset comprising the results of more than 400 physical tests, assembled in [1], has been used as the basis for underpinning the development of predictive analytical expressions.

The stress-strain behaviour of the steel was shown to be well predicted by existing models [15, 19]. The material behaviour of both plasterboard and OSB was shown to be accurately described using the single stage of the Ramberg-Osgood expression up to the ultimate material stress $f_{u}$, both in the longitudinal and transverse direction and both under tension and compression. The Mander [3] model was also found to be capable of accurately capturing the response of plasterboard and OSB in compression while also accounting for the post peak decreasing capacity.

A modified version of the Ramberg-Osgood expression has been employed for modelling the pull-through behaviour of screwed connections both in plasterboard and OSB, up to the ultimate capacity. Linear functions were proposed to account for the observed post-peak behaviour. An expression based on the geometries of the screw and of the board, as well as on the board strength, has been devised for the calculation of the ultimate capacity in pullthrough while the stiffness and ultimate displacement at peak capacity have been expressed as a function of the screw diameter and board thickness.

Regarding the shear behaviour of screwed connections between steel and either plasterboard or OSB, a model consisting of two single Ramberg-Osgood expressions has been adopted to accurately capture the load-slip behaviour up to the ultimate capacity. An extensive investigation into the failure modes of steel-to-board connections revealed that the expressions of EN 1995-1-1 33] for tilting can accurately predict the ultimate capacity of plasterboard while, for OSB, the expressions corresponding to failure due to screw bending for thin plates combined with pull-through yield consistent and accurate capacity predictions. A new empirical expression for the calculation of the embedment strength 
of plasterboard has been developed while the stiffness and ultimate displacement can be expressed in terms of the embedment strength and screw diameter.

All devised models were found capable of accurately capturing the exhibited responses for different sheathing and fastening arrangements and are suitable for use in design by advanced computational analysis, as well as in numerical parametric studies. The devised models, along with the key input test parameters, are provided in a summary table.

\section{Acknowledgements}

Funding for this research was received from the EPSRC Centre for Doctoral Training in Sustainable Civil Engineering at Imperial College London and Ayrshire Metals Limited. The authors would like to thank Viktoria Avgitidou for her contribution to this research.

\section{References}

[1] C. Kyprianou, P. Kyvelou, L. Gardner, D. A. Nethercot, Characterisation of material and connection behaviour in sheathed cold-formed steel wall systems - Part 1: experimentation and data compilation, Structures [Submitted].

[2] W. Ramberg, W. R. Osgood, Description of stress-strain curves by three parameters, Technical Notes 902, National Advisory Committee for Aeronautics, Washington (1943).

[3] J. B. Mander, M. J. N. Priestley, R. Park, Theoretical stress-strain model for confined concrete, Journal of Structural Engineering 114 (8) (1988) 1804-1826.

[4] L. C. M. Vieira Junior, B. W. Schafer, Lateral stiffness and strength of sheathing braced cold-formed steel stud walls, Engineering Structures 37 (2012) 205-213.

[5] K. D. Peterman, B. W. Schafer, Sheathed cold-formed steel studs under axial and lateral load, Journal of Structural Engineering 140 (10) (2014) 04014074.

[6] R. M. Lawson, A. G. Way, M. Heywood, J. B. P. Lim, R. Johnston, K. Roy, Stability of light steel walls in compression with plasterboards on one or both sides, Proceedings of the Institution of Civil Engineers-Structures and Buildings (2019) 1-19.

[7] P. Kyvelou, L. Gardner, D. A. Nethercot, Testing and analysis of composite cold-formed steel and wood- based flooring systems, Journal of Structural Engineering 143 (11) (2017) 04017146.

[8] K. D. Peterman, N. Nakata, B. W. Schafer, Hysteretic characterization of cold-formed steel stud-tosheathing connections, Journal of Constructional Steel Research 101 (2014) 254-264. 
[9] M. Stergiopoulos, R. M. Lawson, P. Lopez, Composite action of fixings to gypsum boards acting in shear based on material properties, Proceedings of the Institution of Civil Engineers-Construction Materials (2019) 1-56.

[10] L. Fiorino, T. Pali, B. Bucciero, V. Macillo, M. T. Terracciano, R. Landolfo, Experimental study on screwed connections for sheathed CFS structures with gypsum or cement based panels, Thin-Walled Structures 116 (2017) 234-249.

[11] S. Selvaraj, M. Madhavan, Sheathing braced design of cold-formed steel structural members subjected to torsional buckling, Structures 20 (2019) 489-509.

[12] H. N. Hill, Determination of stress-strain relations from "offset" yield strength values, National Advisory Committee for Aeronautics, Technical Notes: No. 927, Aluminum Company of America (1944).

[13] K. J. R. Rasmussen, Full-range stress-strain curves for stainless steel alloys, Journal of constructional steel research 59 (1) (2003) 47-61.

[14] E. Mirambell, E. Real, On the calculation of deflections in structural stainless steel beams: an experimental and numerical investigation, Journal of Constructional Steel Research 54 (1) (2000) 109-133.

[15] L. Gardner, X. Yun, Description of stress-strain curves for cold-formed steels, Construction and Building Materials 189 (2018) 527-538.

[16] I. Arrayago, E. Real, L. Gardner, Description of stress-strain curves for stainless steel alloys, Materials \& Design 87 (2015) 540-552.

[17] Y. Liang, T. Manninen, O. Zhao, F. Walport, L. Gardner, Elevated temperature material properties of a new high-chromium austenitic stainless steel, Journal of Constructional Steel Research 152 (2019) 261-273.

[18] L. Gardner, M. Ashraf, Structural design for non-linear metallic materials, Engineering Structures 28 (6) (2006) 926-934.

[19] X. Yun, L. Gardner, Stress-strain curves for hot-rolled steels, Journal of Constructional Steel Research 133 (2017) 36-46.

[20] C. Petrone, G. Magliulo, G. Manfredi, Mechanical properties of plasterboards: experimental tests and statistical analysis, Journal of Materials in Civil Engineering 28 (11) (2016) 04016129.

[21] S. Selvaraj, M. Madhavan, Investigation on sheathing effect and failure modes of gypsum sheathed cold-formed steel wall panels subjected to bending, Structures 17 (2019) 87-101.

[22] E. C. Zhu, Z. W. Guan, P. D. Rodd, D. J. Pope, A constitutive model for OSB and its application in finite element analysis, Holz als Roh-und Werkstoff 63 (2) (2005) 87-93.

[23] R. Plenzler, L. Ludwiczak-Niewiadomska, P. Strzelecki, Elastic and strength properties of OSB layers, Drvna industrija: Znanstveni časopis za pitanja drvne tehnologije 68 (1) (2017) 3-9.

[24] G. Chen, B. He, Stress-strain constitutive relation of osb under axial loading: An experimental inves- 
tigation, BioResources 12 (3) (2017) 6142-6156.

[25] P. Kyvelou, L. Gardner, D. A. Nethercot, Finite element modelling of composite cold-formed steel flooring systems, Engineering Structures 158 (2018) 28-42.

[26] L. C. M. Vieira Junior, B. W. Schafer, Behavior and design of sheathed cold-formed steel stud walls under compression, Journal of Structural Engineering 139 (5) (2013) 772-786.

[27] L. C. M. Vieira Junior, B. W. Schafer, Fastener demands for sheathing-braced cold-formed steel stud gravity walls, Latin American Journal of Solids and Structures 13 (6) (2016) 1167-1185.

[28] P. Kyvelou, L. Gardner, D. A. Nethercot, Composite action between cold-formed steel beams and woodbased floorboards, International Journal of Structural Stability and Dynamics 15 (8) (2015) 1540029.

[29] S. Selvaraj, M. Madhavan, Bracing effect of sheathing in point-symmetric cold-formed steel flexural members, Journal of Constructional Steel Research 157 (2019) 450-462.

[30] S. Selvaraj, M. Madhavan, Studies on cold-formed steel stud panels with gypsum sheathing subjected to out-of-plane bending, Journal of Structural Engineering 144 (9) (2018) 04018136.

[31] S. Selvaraj, M. Madhavan, Investigation on sheathing-fastener connection failures in cold-formed steel wall panels, Structures 20 (2019) 176-188.

[32] J. Ye, X. Wang, M. Zhao, Experimental study on shear behavior of screw connections in CFS sheathing, Journal of Constructional Steel Research 121 (2016) 1-12.

[33] EN 1995-1-1, Eurocode 5: Design of timber structures - Part 1-1: General - Common rules and rules for buildings, European Committee for Standardization, Brussels, Belgium (2004).

[34] EN 520, Gypsum plasterboards - Definitions, requirements and test methods, European Committee for Standardization, Brussels, Belgium (2009).

[35] L. Vieira, B. W. Schafer, Experimental results for translational stiffness of stud-sheathing assemblies, Tech. rep., AISI-COFS Project on Sheathing Braced Design of Wall Studs (2009).

[36] K. D. Peterman, B. W. Schafer, Hysteretic shear response of fasteners connecting sheathing to coldformed steel studs, Research report, CFS-NEES, RR04 (2013).

[37] L. Fiorino, G. Della Corte, R. Landolfo, Experimental tests on typical screw connections for cold-formed steel housing, Engineering Structures 29 (8) (2007) 1761-1773.

[38] R. L. Serrette, J. Encalada, M. Juadines, H. Nguyen, Static racking behavior of plywood, osb, gypsum, and fiberbond walls with metal framing, Journal of Structural Engineering 123 (8) (1997) 1079-1086. 